ФІЗИКА СОНЦЯ

КІНЕМАТИКА

I ФІЗИКА

НЕБЕСНИХ

ТІЛ том 35 № 22019

doi: https://doi.org/10.15407/kfnt2019.02.003

УДК 523.985 .3

\title{
М. Н. Пасечник
}

Главная астрономическая обсерватория Национальной академии наук Украины ул. Академика Заболотного 27, Киев, 03143 rita@mao.kiev.ua

\section{Движение фотосферного вещества на участке активной области с двумя бомбами Эллермана}

Представлены результаты анализа особенностей изменений лучевых скоростей плазмы в разных слоях фотосферы активной области NOAA 11024 под действием двух возникших и развивающихся бомб Эллермана (БЭ-1 и БЭ-2). Спектральные данные с высоким пространственным и временным разрешением были получены на франкоитальянском солнечном телескопе THEMIS 4 июля 2009 г. Время наблюдений 20 мин. В день наблюдений АО находилась на стадии резкого роста активности, и бомбы Эллермана развивались в области одного из трех выходящих в это время магнитных потоков. Во время наших наблюдений БЭ-1 находилась на стадии затухания, а яркость БЭ-2 увеличивалась. Использован участок спектра $\lambda \approx 630$ нм, включающий фотосферные линии, которые формируются в большом диапазоне высот: линии нейтрального железа Fе I $\lambda$ 630.15, 630.25, 630.35 нм и линию титана Ті I $\lambda 630.38$ нм. Определены и проанализированы изменения скорости и направления движения вещества в областях бомб Эллермана и в их ближайших окрестностях на разных уровнях фотосферы и на разных стадиях развития БЭ. Исследования показали, что на всех уровнях фотосферь АО происходил преимущественно подъем вещества. При этом в местах расположения БЭ наблюдалось заметное уменьшение величины лучевых скоростей $V_{\text {луи }}$ и амплитудь их колебаний. Вероятно, сверху шли потоки вещества, которые уменьшали скорость восходящего движения плазмы. Это указывает на то, что мелкомасштабные нисходящие движения, вызванные магнитными пересоединениями, накладывались на крупномасштабное восходящее движение плазмы нового магнитного потока. Этот вывод подтверждает и форма профилей фотосферных линий. Профили сильных линий имели красную асимметрию. Скорость вещества, определенная по смещению компонента, которыйхорошо выделялся в красном крыле профилей линии Fе I 630.35 нм, доходила до

(C) М. Н. ПАСЕЧНИК, 2019 


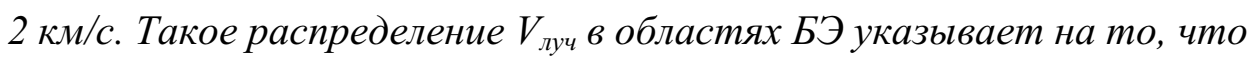
они состояли из нескольких струй, движущиися с разными скоростями и в разных направлениях. В центральной части БЭ-1 и БЭ-2 в верхнем слое фотосферы лучевая скорость изменялась в пределах $-1 \ldots 0$ и -1..0.2 км/c, а в нижнем слое фотосферы - в пределах $-1.6 \ldots-0.2$ и $-1.1 . .0 .25 \mathrm{kM} / \mathrm{c}$ соответственно. В окрестностях бомб

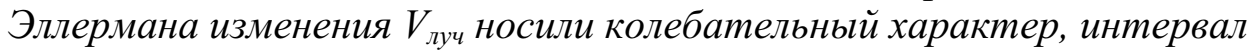
между колебаниями составлял около 5 мин. В областях БЭ картина квазипериодических колебаний $V_{\text {луч }}$ нарушалась, во многих случаях они происходили в противофазе. На основе проведенных исследований можно сделать вывод, что возбуждение, вызванное импульсным выделением энергии в результате последовательных магнитных пересоединений, связанных с выходом нового магнитного потока, распространилось из области БЭ-1 вдоль магнитной петли и вызвало появление БЭ-2, затем они развивались как физически связанная пара. Изученные особенности изменения лучевых скоростей хромосферного и фотосферного вещества указывает на то, что во время развития БЭ наблюдалось разнонаправленное движение - в нижнем слое хромосферы вещество двигалось вверх, а также образовались потоки, которые двигались вниз, уменьшая скорость восходящего движения плазмы на уровне фотосферы. Такое распределение скоростей могли вызвать магнитные пересоединения, которые происходили в слое между верхней фотосферой и нижней хромосферой, где формировалось ядро линии $H_{\alpha}$.

Ключевые слова: Солние, фотосфера, бомбы Эллермана, спектральное исследование, лучевые скорости.

\section{ВВЕДЕНИЕ}

Бомбы Эллермана (БЭ) являются частью солнечной активности и широко изучаются в последние годы. Их основные морфологические свойства описаны в работах $[16,17,26,30]$. Это короткоживущие, мелкомасштабные яркие структуры в атмосфере Солнца, связанные с быстрым локальным выделением энергии, с магнитными полями и специфическими движениями плазмы. Было установлено, что типичный размер БЭ - около 1", время жизни - около 10...20 мин. Наблюдаются БЭ в крыльях сильных хромосферных линий, в УФ-континууме, а также в линиях Са II Н и К, Са II $\lambda 854.2$ нм [12, 20, 21, 29, $32,33,35]$. Впервые спектры БЭ были получены Вальтером Митчелом в 1909 г. и Фердинандом Эллерманом в 1915 г. и описаны им в 1917 г. в работе [14]. Наиболее очевидной характеристикой спектров БЭ являются яркие узкие эмиссионные полосы (длиной $\Delta \lambda=0.7 \ldots 1.0 \mathrm{Hм}$ ) в обоих крыльях хромосферных линий и сильное поглощение в их центре. Позднее это явление получило еще одно название - усы (moustaches) [9]. Наблюдения показывают, что бомбы Эллермана возникают преимущественно в молодых развивающихся активных об- 
ластях (AO) со сложной магнитной структурой, в областях выходящих магнитных потоков и в окрестностях солнечных пятен. Было также установлено, что большинство БЭ располагаются под системами арочных волокон. Наблюдения [41] показали, что 50 \% бомб Эллермана появляются и исчезают попарно и, вероятно, являются основаниями компактных магнитных петель. Как правило, БЭ в такой паре развиваются синхронно.

Много работ посвящено изучению механизма образования бомб Эллермана. В последнее время большинство исследователей пришли к выводу, что БЭ, как и вспышки, образуются в результате магнитных пересоединений, но в более глубоких слоях солнечной атмосферы при большой плотности вещества и напряженности магнитного поля [11, $12,16,17,36,3839]$.

Одной из проблем, связанных с бомбами Эллермана, является не до конца решенный вопрос - в каком слое атмосферы Солнца происходят магнитные пересоединения, вызывающие их образование [12]. Предполагают, что во время развития БЭ энергия магнитного поля расходуется в основном на ускорение потоков плазмы. Образуются струи вещества, идущие от места пересоединения - наблюдается разнонаправленное движение. Изучение особенностей движения вещества на разных уровнях атмосферы Солнца во время развития БЭ поможет ответить на вопрос, на какой высоте в атмосфере Солнца формируются БЭ.

Во многих работах изучались скорость и направление движения вещества в областях бомб Эллермана $[2,6,7,19,28,30,32]$. То, что в результате магнитных пересоединений формируются двунаправленные потоки, показали как моделирование БЭ, так и наблюдения.

В работе [28] на основе спектральных наблюдений за потоками газа в бомбах Эллермана было установлено, что двунаправленные потоки начинались между нижней фотосферой и нижней хромосферой. Для исследования были использованы хромосферная линия $\mathrm{H}_{\alpha}$ и линия Тi II $\lambda$ 655.9576, которая формируется в нижнем слое фотосферы. По доплеровским сдвигам линий были получены значения скорости восходящего потока в хромосфере $1 \ldots 3 \mathrm{\kappa m} / \mathrm{c}$ и скорости нисходящего потока в фотосфере - около $0.2 \mathrm{kм} / \mathrm{c}$. Авторы пришли к выводу, что магнитные пересоединения, в результате которых образовались бомбы Эллермана, происходили в слое между нижней фотосферой (0..200 км) и нижней хромосферой (400...1200 км).

Наблюдения показали, что часто БЭ сопровождают небольшие хромосферные выбросы - сержи (surges), которые, как считается, свидетельствуют о магнитных пересоединениях в нижней хромосфеpe $[16,28,29,41]$.

В работе [12] были использованы наблюдения БЭ в линии $\mathrm{H}_{\alpha}$ и в УФ-континууме вблизи $\lambda=160$ нм, а в работе [11] — набор из двух линий $\mathrm{H}_{\alpha}$ и Са II Н. НеЛТР-модели, которые хорошо воспроизводили наблюдаемую эмиссию, показали, что БЭ формировались близко к области температурного минимума или в нижней хромосфере. В работе 
[34] было подтверждено, что БЭ высвобождают энергию в диапазоне нескольких высот шкалы вокруг температурного минимума таким образом, что они влияют как на фотосферу, так и на нижнюю хромосферу. В работах $[16,22,23]$ получен вывод, что БЭ обусловлены последовательными и прерывистыми магнитными пересоединениями в нижней хромосфере или в верхней фотосфере.

В работе [31] было показано, что БЭ могут формироваться с помощью фотосферных магнитных пересоединений, а в работе [38], на основе того что убедительных доказательств влияния БЭ на внешнюю атмосферу нет, было высказано предположение, что бомбы Эллермана - чисто фотосферное явление, которое не в состоянии проникнуть в вышележащую атмосферу. В исследовании [13] показано, что магнитные пересоединения могут происходить на разных уровнях хромосферы и фотосферы без предпочтительной высоты.

Значения скорости движения вещества вверх на уровне хромосферы согласно разным исследованиям составляли $15 \ldots 18$ км/с [2], $1 \ldots 3 \mathrm{\kappa м} / \mathrm{c}[28]$ и $6 \ldots 8 \mathrm{\kappa м} / \mathrm{c}[22,26]$. Во время развития двух БЭ были обнаружены восходящие потоки со скоростями до 9 км/с на уровне образования ядра линии $\mathrm{H}_{\alpha}$ [7]. С другой стороны, было найдено, что более 80 \% БЭ связаны с нисходящими движениями фотосферного вещества со скоростями $0.1 \ldots 0.5$ км/с $[10,19,39]$. Временные кривые лучевой скорости в верхних и нижних слоях фотосферы на участке АО с развивающейся БЭ приведены в работе [6].

Цель нашей работы - изучить особенности изменений лучевых скоростей вещества в разных слоях фотосферы активной области NOAA 11024 под действием возникших и развивающихся двух бомб Эллермана (БЭ-1 и БЭ-2), которые наблюдались 4 июля 2009 г. Данная работа является продолжением работ $[7,8]$, в которых представлены результаты анализа спектральных наблюдений этих двух БЭ в линии $\mathrm{H}_{\alpha}$, а также рассмотрены особенности изменений фраунгоферовых линий, образующихся в разных слоях фотосферы, в спектрах бомб Эллермана и их окрестностей, полученных на разных стадиях развития БЭ.

\section{НАБЛЮДАТЕЛЬНЫЙ МАТЕРИАЛ}

Исследуемые в данной работе две бомбы Эллермана возникли и развивались как физически связанная пара в активной области NOAA 11024 [7]. В день наблюдений, 4 июля 2009 г., АО находилась на солнечном диске возле центрального меридиана (S25E02 $(-29,-449))$. Активность ее быстро росла [15, 37], и бомбы Эллермана развились в области одного из трех выходящих в это время магнитных потоков.

Наблюдения одновременно в нескольких участках спектра были проведены Е. В. Хоменко на франко-итальянском 90-см вакуумном телескопе THEMIS Института астрофизики на Канарских островах (Испания, остров Тенерифе). В предыдущих работах [6, 7] подробно описан использованный нами спектральный материал. 


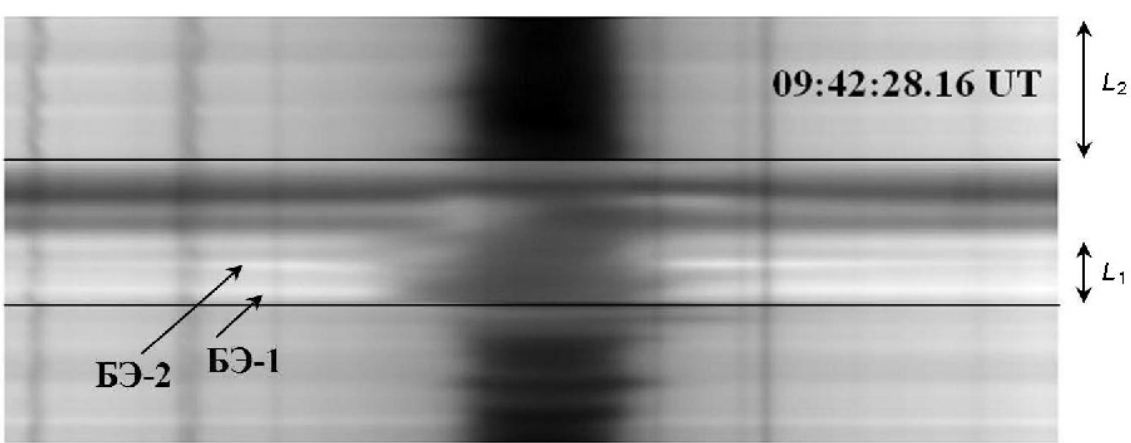

Puc. 1. $\mathrm{H}_{\alpha}$-спектр АО, полученный в момент наблюдения $9^{h} 42^{m} 28^{s} \mathrm{UT}$ (БЭ-1 и БЭ-2 - бомбы Эллермана, $L_{1}$ - исследуемый участок, $L_{2}$ - участок спектра АО без активных образований и вне области выходящего магнитного потока)

На рис. 1 представлен $\mathrm{H}_{\alpha}$-спектр, полученный в $9^{h} 42^{m} 28^{s} \mathrm{UT}$. На нем показаны хорошо выделяющиеся бомбы Эллермана БЭ-1 и БЭ-2, исследуемый участок спектра $L_{1}$, участок спектра $\mathrm{AO}$ без активных образований $L_{2}$.

Для исследования изменений лучевых скоростей плазмы на уровне фотосферы во время развития бомб Эллермана был использован участок спектра $\lambda \approx 630$ нм (рис. 2 [8]). Он включает фраунгоферовы линии, которые формируются в большом диапазоне высот: две сильные линии нейтрального железа Fe I $\lambda 630.15$ нм $\left(d_{0}=0.719\right), 630.25$ нм $\left(d_{0}=0.650\right)$ и две слабые линии - Fe I $\lambda 630.35$ нм $\left(d_{0}=0.045\right)$ и линию титана Ті I $\lambda 630.38$ нм $\left(d_{0}=0.072\right)$, где $d_{0}$ - центральная глубина профиля, полученного для центра диска Солнца [8]. В тексте линии условно обозначены Fe-1, Fe-2, Fe-3 и Ті соответственно. Высоты $h$ образования центров этих линий, полученных для невозмущенной фотосферы в центре диска Солнца, равны 489, 381, 139, 180 км соответственно. Как отмечено в предыдущих работах $[8,24]$, в случае активной области мы можем говорить только о верхних и нижних слоях фотосферы, в которых сформировались две сильные и две слабые линии.

\section{ИЗМЕНЕНИЯ ФОТОСФЕРНЫХ ЛУЧЕВЫХ СКОРОСТЕЙ ВЕЩЕСТВА АКТИВНОЙ ОБЛАСТИ В БОМБАХ ЭЛЛЕРМАНА И ИХ ОКРЕСТНОСТЯХ}

В работе были использованы I-профили Стокса, полученные с интервалом, соответствующим расстоянию на Солнце 160 км. Лучевые скорости $V_{\text {луч }}$ фотосферного вещества на уровнях образования исследованных в работе фраунгоферовых линий определялись по доплеровским смещениям ядер линий относительно их положений в лабораторном спектре с использованием близлежащих теллурических линий. При этом учитывались все необходимые поправки: за вращение Земли вокруг своей оси и вокруг Солнца, вращение Солнца и гравитационное смещение. Смещение спектральных линий в коротковолновую 
сторону указывает на восходящие потоки плазмы, а смещение в длинноволновую сторону - на движение вниз. Так как на исследуемом участке спектра находились теллурические линии кислорода, положение которых можно было определить с большой точностью, погрешность вычисления фотосферных скоростей была небольшой и составляла $0.1 \mathrm{\kappa м} / \mathrm{c}[6]$.

Особенности движения фотосферного вещества на участке AO без активных образований. Для того чтобы выявить изменения движения фотосферного вещества, которые произошли на участке АО $L_{1}$ под влиянием развивающихся бомб Эллермана, мы исследовали распределение лучевых скоростей на участке активной области без активных образований и вне области выходящих магнитных потоков (участок $L_{2}$ на рис. 1 ). Спектры этих участков были получены одно-

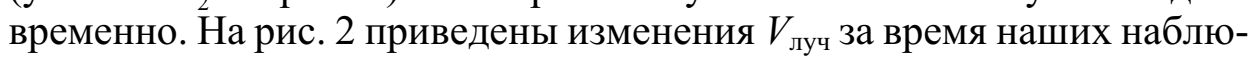
дений на уровнях образования исследованных в работе фраунгоферовых линий в областях гранулы и соседнего с ней межгранульного промежутка [8]. Как отмечено в работе [5], понятие гранулы с горячим поднимающимся веществом и межгранулы с холодным опускающимся веществом относится только к уровню образования континуума. Применив корреляционный анализ к данным спектральных наблюдений линий нейтрального и ионизованного железа в спокойной фотосфере Солнца, авторы показали, что на всех других высотах фотосферы можно обнаружить самые разнообразные сочетания направления движения вещества - была рассмотрена 16-колончатая модель. Мы исследуем фотосферу активной области, которая находилась на ранней стадии развития [24]. На рис. 2 видно, что кривые изменения $V_{\text {луч }}$ для всех исследуемых высот фотосферы хорошо коррелируют между

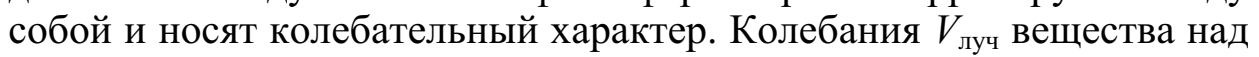
гранулой (рис. 2а) происходили с интервалом от 3 до 5 мин, над межгранулой они были выражены более ярко и происходили с интервалом

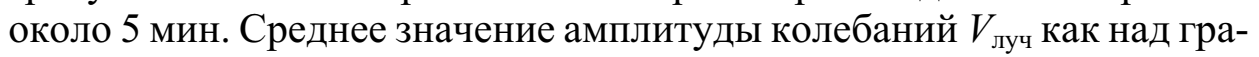
нулой, так и над межгранулой составляло около 1 км/с, а максимальное - около 1.6 км/с. За время наших наблюдений как в верхнем, так и в нижнем слое фотосферы над гранулой вещество двигалось вверх, над межгранулой происходил как подъем, так и опускание вещества. Лучевая скорость над гранулой (рис. 2a) на высотах образования Fe-1 и $\mathrm{Fe}-2$ изменялась со временем в пределах $0.1 \ldots-1.8 \mathrm{\kappa м} / \mathrm{c}$ и $-0.1 \ldots$ -2.0 км/с соответственно. В нижней фотосфере (на высотах

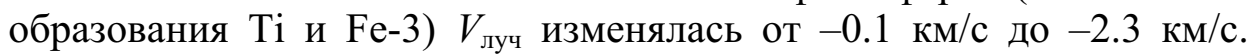
Хорошо видно, что скорость вещества уменьшалась с увеличением высоты фотосферы. Например, в момент наблюдений $9^{h} 34^{m} 17^{s} \mathrm{UT}$ на

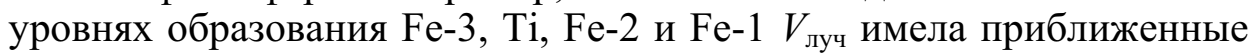
значения $-1.4,-1.3,-1.0$ и $-0.7 \mathrm{\kappa m} / \mathrm{c}$ соответственно, т. е. в нижнем слое фотосферы вещество двигалось в два раза быстрее, чем в верхнем слое. На рис. $2 б$ видно, что над межгранульным промежутком разброс значений $V_{\text {луч }}$ с высотой фотосферы был меньшим, чем над гранулой, и составлял в среднем около 0.3 км/с. Это связано с наличием сильных 

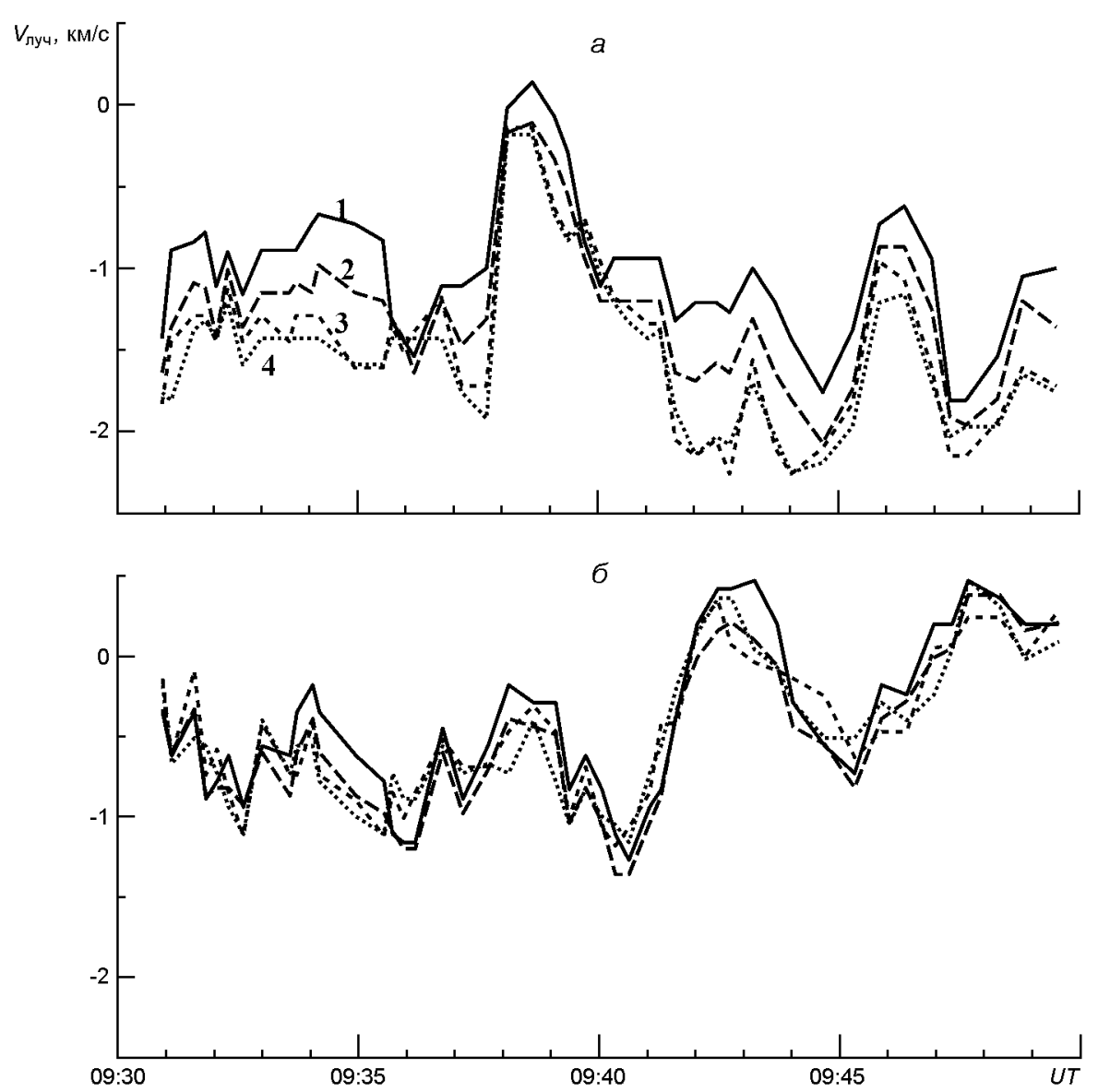

$P u c$. 2. Временные изменения лучевой скорости, вычисленной по доплеровским смещениям ядер фотосферных линий в спектрах участка $L_{2}: a-$ в области гранулы и над ней, $\sigma-$ в области межгранульного промежутка и над ним. Цифры $1-4$ - для линий $\mathrm{Fe}-1, \mathrm{Fe}-2, \mathrm{Ti}$ и $\mathrm{Fe}-3$ соответственно. Отрицательные значения лучевой скорости соответствуют смещениям линий в коротковолновую часть спектра, т. е. движениям по направлению к наблюдателю

магнитных полей внутри межгранульных полос. За время наших наблюдений лучевая скорость вещества в этой области изменялась в пределах $0.5 \ldots-1.2 \mathrm{\kappa м} / \mathrm{c}$.

Интересно сравнить полученные нами результаты для фотосферы участка активной области с аналогичными данными, полученными для спокойной фотосферы Солнца. В работах [3, 4] на основании статистического анализа данных наблюдений линии Fe I $\lambda 532.4185$ нм получено, что над гранулами и межгранулами колебания вещества происходят с разными периодами. Над гранулами вещество колеблется в основном с периодом 312 с, а над межгранулами - 268 с. Максимальные флюктуации скорости при наблюдениях в линии Fe I $\lambda$ 532.4185 нм (формируется в верхней фотосфере) могут достигать 1 км/с. Сделан вывод, что колебания скорости фотосферного вещества в гранулах и межгранульных промежутках различаются из-за различия физических условий в них. 
Изменение $V_{\text {луи }}$ по площади исследуемого участка АО с двумя развивающимися бомбами Эллермана. Были исследованы особенности изменения фотосферной лучевой скорости вдоль участка $\mathrm{AO}$, вырезанного щелью спектрографа, на разных уровнях образования четырех фраунгоферовых линий. На рис. 3 представлено изменения $V_{\text {луч }}$ в моменты наблюдений, когда происходило увеличение яркости БЭ (см. рис. 10 в работе [8]). Видно, что на всем участке $L_{1}$ плазма преимущественно двигалась вверх. При этом выделились два участка, на которых наблюдалось заметное уменьшение величин лучевых скоростей по сравнению с их ближайшими окрестностями. Если сравнить кривые на рис. 3 с кривыми изменения интенсивности в центрах линий (рис. 9 в работе [8]) видно, что эти участки соответствуют областям развития бомб Эллермана.

На рис. За видно, что на кривой 1 , полученной для линии $\mathrm{Fe}-1$, уже в первый момент наблюдения четко выделяются два участка, на которых на 60 \% понижена скорость подъема фотосферного вещества по сравнению с их окрестностями (от -1.66 до -0.64 км/с). Примерно через минуту (в $9^{h} 32^{m} 04^{s}$ UT) скорость подъема в области БЭ-1 (кривая 2) уменьшилась еще на $17 \%$ (до -0.35 км/c), а в области БЭ-2 - на $11 \%$ (до -0.45 км/с). Лучевая скорость уменьшалась и в окрестностях

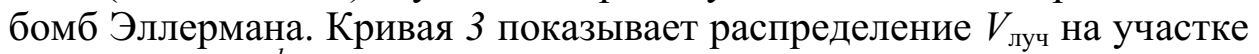
$\mathrm{AO}$ в момент $9^{h} 33^{m} 01^{s} \mathrm{UT}$. Лучевая скорость в центральных областях БЭ-1 и БЭ-2 в это время составляла -0.18 км/с и -0.35 км $/ \mathrm{c}$ соответственно. В момент самого большого повышения яркости БЭ-1 $\left(9^{h} 34^{m} 03^{s} \mathrm{UT}\right)$ в обоих бомбах Эллермана наблюдалось опускание вещества с небольшой скоростью 0.05 км/с (кривая 4). Напомним, что во время наших наблюдений яркость БЭ-1 уменьшалась, а БЭ-2 увеличивалась. Видно, что в первые 4 мин наших наблюдений, когда происходили магнитные пересоединения в области БЭ-1, вызвавшие появление БЭ-2, скорости подъема фотосферного вещества в области БЭ-1 уменьшались на бо́льшую величину, чем в области БЭ-2, которая только начала развиваться [8]. Кривые 5-7 показывают, что до конца наблюдений в области БЭ-1 скорость подъема вещества постепенно увеличивалась, в один из последних моментов наблюдений (кривая 7) ее значение в центральной части БЭ составляло -0.95 км/с. В области БЭ-2 в это время (кривая 7 построена для момента максимальной яркости БЭ-2 за время наших наблюдений) происходили колебания $V_{\text {луч }}$ между -0.1 км/с и -0.4 км/с, т. е. ее величины были меньшими, чем в области БЭ-1.

Интересно отметить, что на кривых изменения остаточной интенсивности в центре линии Fe-1 максимум соответствующий БЭ-2 начал выделяться через 5 мин после начала наблюдений, а еще через 2 мин он стал уже четко виден [8]. На кривых изменения скорости вдоль участка $\mathrm{AO}$ на уровне образования линии $\mathrm{Fe}-1$ максимум, соответствующий развивающейся БЭ-2, был хорошо виден уже в первый момент наблюдений. Это значит, что изменения скорости в области образования БЭ-2 произошли раньше, чем увеличилась ее яркость. 

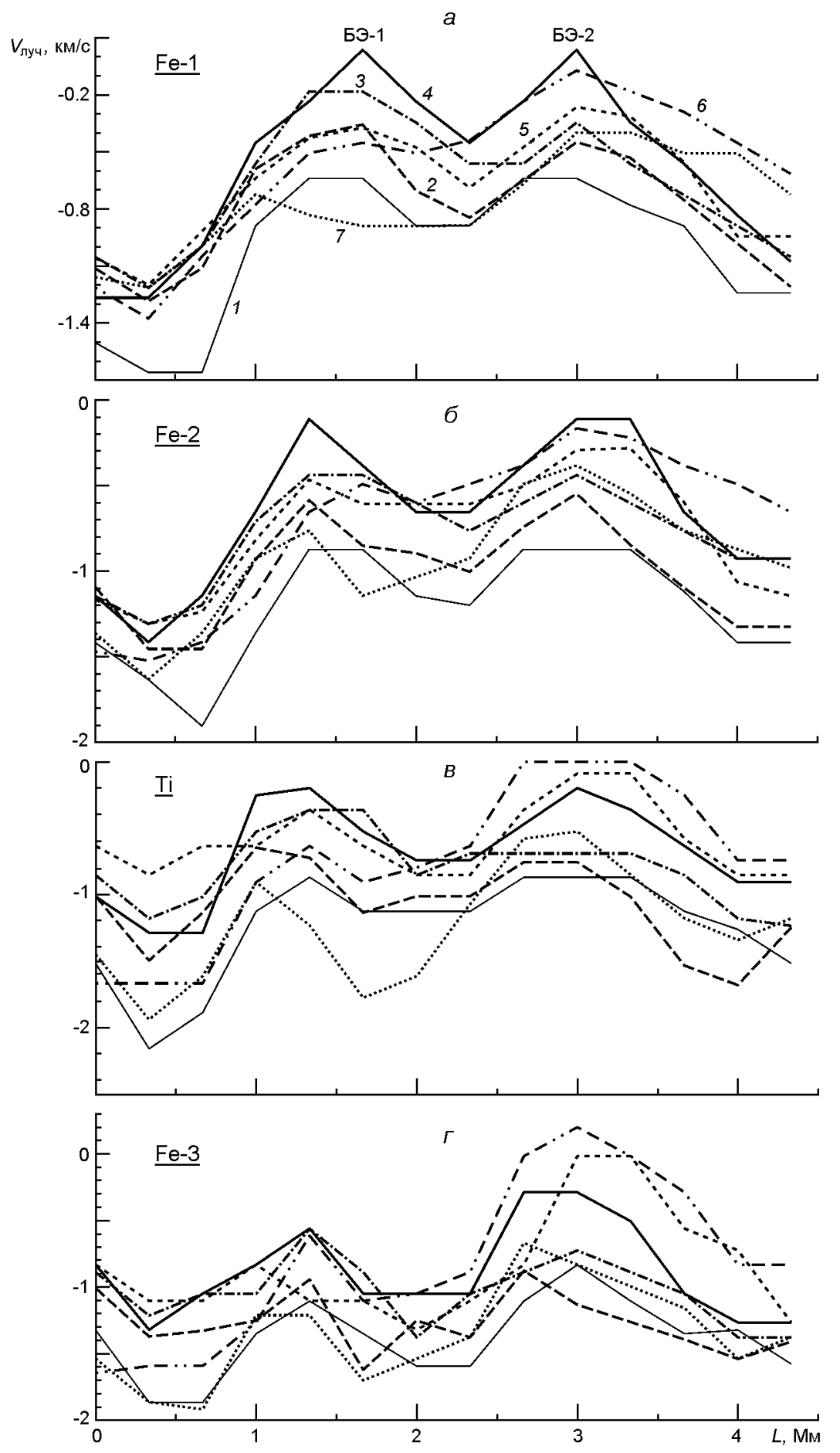

Puc. 3. Распределение лучевой скорости вдоль участка $L_{1}$ на разных уровнях фотосферы (линии $\mathrm{Fe}-1, \mathrm{Fe}-2, \mathrm{Ti}$ и $\mathrm{Fe}-3$ ) в разные моменты наблюдений: кривые $1-7$ получены для моментов времени $09^{h} 30^{m} 56^{s}, 32^{m} 04^{s}, 33^{m} 01^{s}, 34^{m} 03^{s}, 38^{m} 07^{s}, 42^{m} 28^{s}$ и $47^{m} 40^{s}$ UT соответственно 


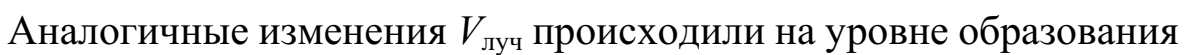
линии $\mathrm{Fe}-2$ (рис. 3б), однако значения скорости в соответствующие моменты наблюдений в области БЭ-1 и БЭ-2 были в среднем соответственно на $30 \%$ и $10 \%$ выше, чем на уровне образования линии $\mathrm{Fe}-1$.

В верхнем слое фотосферы за время наблюдений в окрестности

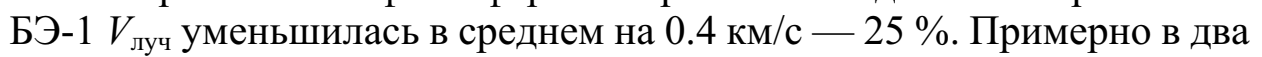

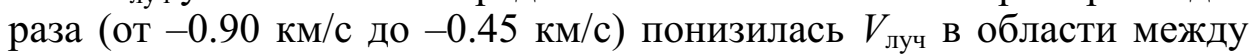
бомбами Эллермана и в окрестности БЭ-2 (от $-1.25 \mathrm{\kappa м} / \mathrm{c}$ до -0.62 км/с).

В нижнем слое фотосферы (рис. 3в и 3г), как и в верхнем, уже в первый момент наблюдений хорошо видны два участка с пониженной скоростью восходящего движения вещества. В слое, где формировалась линия $\mathrm{Ti}$, изменения $V_{\text {луч }}$ вдоль исследуемого участка $\mathrm{AO}$ были такими же, как и в верхнем слое, но значения скорости были выше на $20 \ldots 50 \%$. На рис. 3Г видно, что распределение $V_{\text {луч }}$ в слое, где

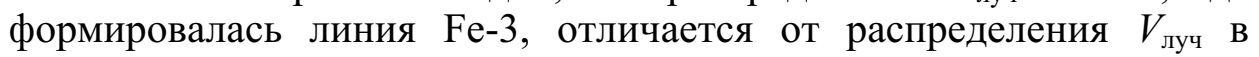
верхнем слое фотосферы. В области БЭ-1 скорость движения вещества вверх была больше, чем в области БЭ-2 на протяжении всего времени наблюдений. Вероятно, это указывает на то, что в самом нижнем из исследуемых слоев фотосферы наличие БЭ-1 повлияло наименьше.

Потоки вещества, вызванные магнитными пересоединениями. Подобные результаты изменений скорости движения вещества БЭ на фотосферном уровне были получены в работе [19]. Было найдено, что более 80 \% БЭ связаны с нисходящими движениями плазмы со скоростями $0.1 \ldots 0.5$ км/с. Однако в областях некоторых БЭ доплеровские скорости показывали восходящие движения. Был сделан вывод, что мелкомасштабные нисходящие движения налагались на макроскопические восходящие движения плазмы. При этом в месте расположения БЭ явно наблюдались локальные минимумы скоростей.

В нашем случае фотосферное вещество на исследуемом участке $L_{1}$ активной области поднималось, но при этом в местах расположения БЭ наблюдалось заметное уменьшение величины лучевых скоростей. Такие особенности движения вещества, вероятно, можно объяснить тем, что сверху шли потоки, которые уменьшали скорость восходящего движения плазмы. Мелкомасштабные нисходящие движения, вызванные магнитными пересоединениями, накладывались на крупномасштабное восходящее движение плазмы нового магнитного потока.

То, что сверху шли потоки вещества, подтверждает форма профилей фотосферных линий. Известно, что асимметрия профилей спектральных линий отражает динамические процессы, происходящие в атмосфере Солнца. Профили сильных линий, которые формировались в верхнем слое фотосферы, имели красную асимметрию, что указывает на то, что в этой области вещество двигалось как вверх, так и вниз. На pис. 4а показаны бисекторы профилий линий $\mathrm{Fe}-1$ и $\mathrm{Fe}-2$ в спектре БЭ-1, полученном в момент резкого увеличения ее яркости $\left(9^{h} 34^{m} 03^{s}\right.$ $\mathrm{UT})$. Бисектор 1 приведен для сравнения, он получен по профилю 

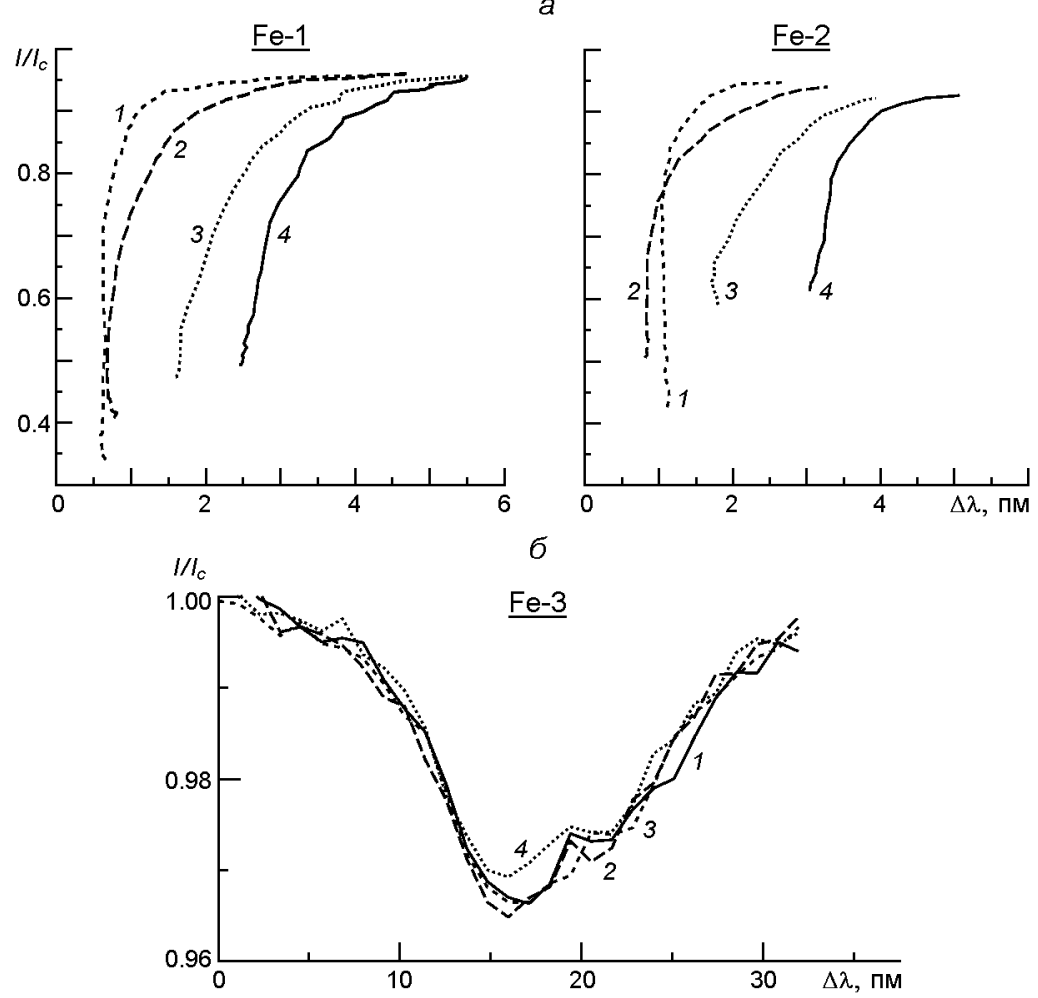

Puc. 4. $a-$ бисекторы профилей фраунгоферовых линий $\mathrm{Fe}-1$ и $\mathrm{Fe}-2$ в спектре БЭ-1, на разных расстояниях от ее центра для момента наблюдений $9^{h} 34^{m} 03^{s} \mathrm{UT}(1-$ вне БЭ-1, 2-4 на расстоянии $-0.67,-0.33,0.0$ Мм от ее центра); $\sigma$ - профили линии $\mathrm{Fe}-3$ для моментов наблюдений $9^{h} 32^{m} 04^{s}, 34^{m} 17 \mathrm{~s}, 39^{m} 43^{s}$ и $44^{m} 02^{s} \mathrm{UT}$ (кривые $1-4$ )

разреза спектра участка АО вне БЭ, бисектор 4 - по профилю спектра центра БЭ, а бисекторы $2-3-$ по профилям, полученным для расстояний -0.67 и -0.33 Мм от центра БЭ. Хорошо виден наклон бисекторов $2-4$ в красную сторону спектра.

Более ярко была выражена асимметрия у профилей фраунгоферовых линий, формировавшихся в нижних слоях фотосферы. Профили, полученные для центральной части БЭ-1, во время резких повышений интенсивности имели несколько компонентов в красном крыле. Вероятно, они были связаны с нисходящими струями фотосферного вещества. На рис. 4 приведены профили линии Fе-3. Хорошо выделяются компоненты в красном крыле линии. Скорость вещества, определенная по смещению этого компонента, доходила до 2 км/с, т. е. БЭ в этой области состояли из нескольких струй, движущихся с разными скоростями и в разных направлениях.

Временные изменения $V_{\text {луч }}$ на исследуемом участке АО. Были исследованы особенности движения фотосферного вещества за время наших наблюдений на участке АО, где развивались бомбы Эллермана. На рис. 6 и 7 представлены временные кривые изменения лучевой скорости плазмы в разных слоях фотосферы в областях БЭ-1 и БЭ-2: в их 


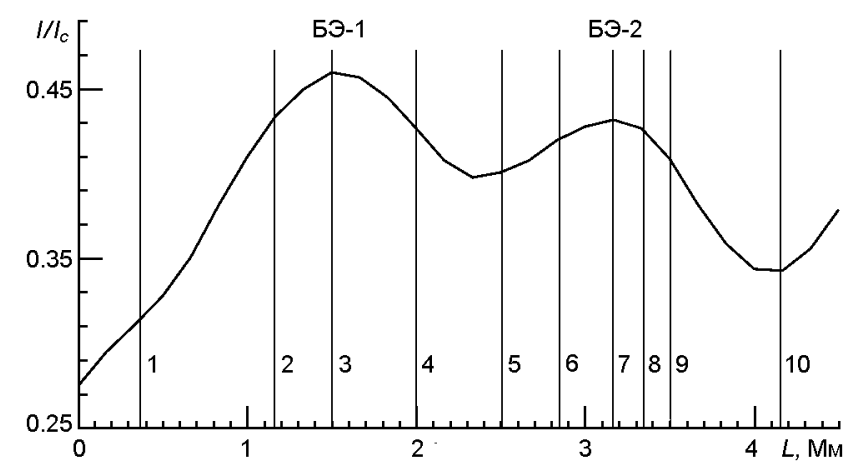

Puc. 5. Изменение центральной интенсивности линии Fe-1 вдоль щели спектрографа для момента наблюдений $9^{h} 42^{m} 28^{s} \mathrm{UT}$, вертикальными линиями $1-10$ указаны места разрезов

центральных частях, на разных расстояниях от них, а также в ближайших окрестностях бомб Эллермана. На рис. 5 указаны места разрезов участка $L_{1} \mathrm{AO}$, для которых изучалось изменение $V_{\text {луч }}$ со временем.

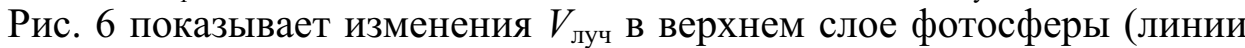
$\mathrm{Fe}-1$ и $\mathrm{Fe}-2$ ), для сравнения приведены изменения хромосферной лучевой скорости, определенные по смещению ядра линии $\mathrm{H}_{\alpha}$ [7]. Заметим, что распределение скоростей в фотосфере имело более тонкую структуру, чем в хромосфере. Рис. 7 показывает изменения $V_{\text {луч }}$ в нижней фотосфере (линии Fe-3 и Тi). Вывод, сделанный в работах [7, 8] на основе изучения временных изменений интенсивностей фраунгоферовых линий в спектрах исследуемого участка АО, о том, что БЭ-1 и БЭ-2 развивались как физически связанная пара, подтверждают и изменения поля скоростей в областях бомб Эллермана.

Видно, что все временные кривые $V_{\text {луч}}$, как и временные кривые изменения яркости [8], представляют собой ряд последовательных пиков, указывая на то, что выделение энергии в бомбах Эллермана происходило в результате последовательных прерывистых магнитных пересоединений. В работах $[16,22,23]$ было найдено, что БЭ связаны с сильными магнитными полями внутри межгранульных полос. Было высказано предположение, что колебания скорости вызывают деформацию магнитного поля необходимую, чтобы вызвать вынужденные повторные пересоединения. Из сравнения рис. 6 и 7 и рис. 10 из работы [8] видно, что пикам уменьшения $V_{\text {луч }}$ восходящего движения фотосферного вещества соответствуют пики увеличения яркости БЭ-1. Для БЭ-2 это соотношение выполнялось не всегда. Так, к концу наблюдений яркость БЭ-2 увеличивалась, при этом скорость движения вещества вверх также увеличивалась.

В нашей предыдущей работе [7] было найдено, что исследуемые бомбы Эллермана сопровождались несколькими небольшими кратковременными выбросами хромосферного вещества (сержами). На рис. 6 они отмечены стрелками. Считается, что выбросы вещества происходят во время пересоединений. Действительно, в это время наблюдалось понижение скорости движения вещества вверх. Наблюдалось разнонаправленное движение. 

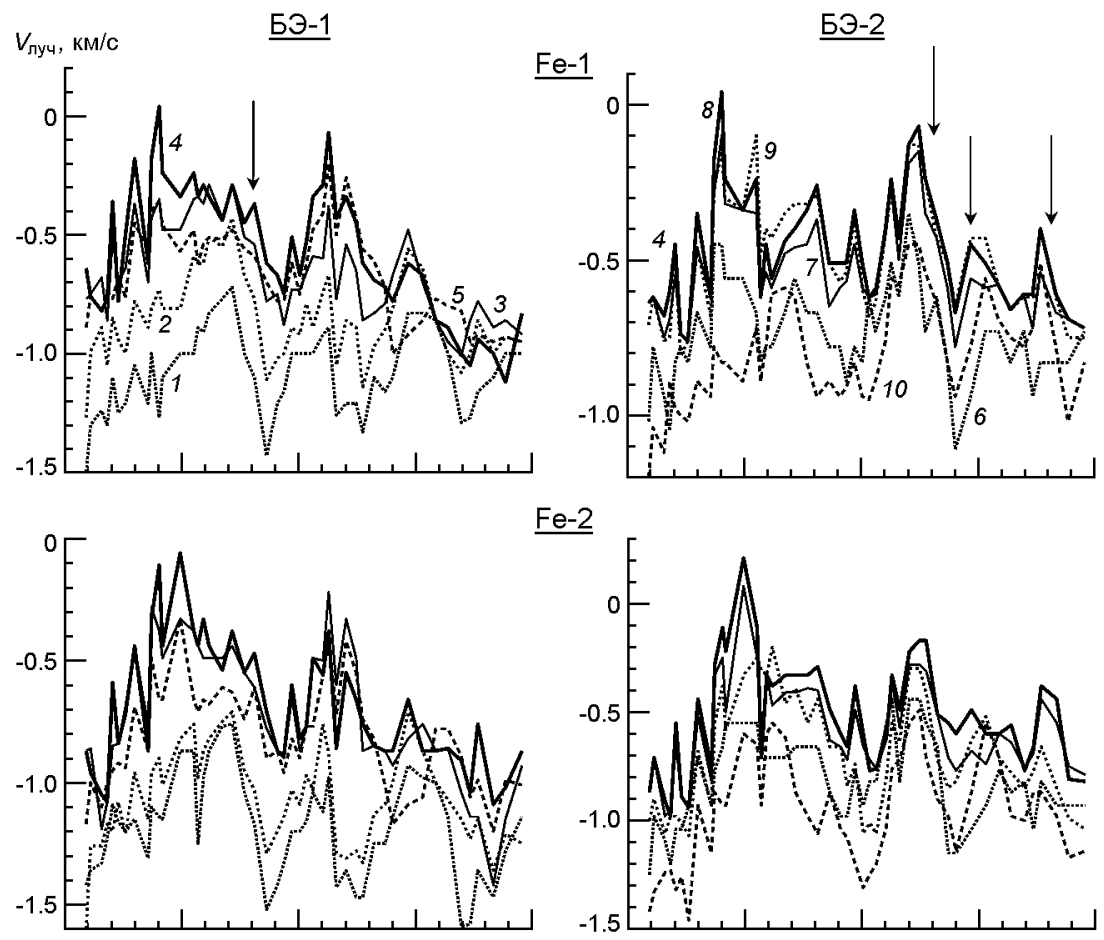

Fe-2
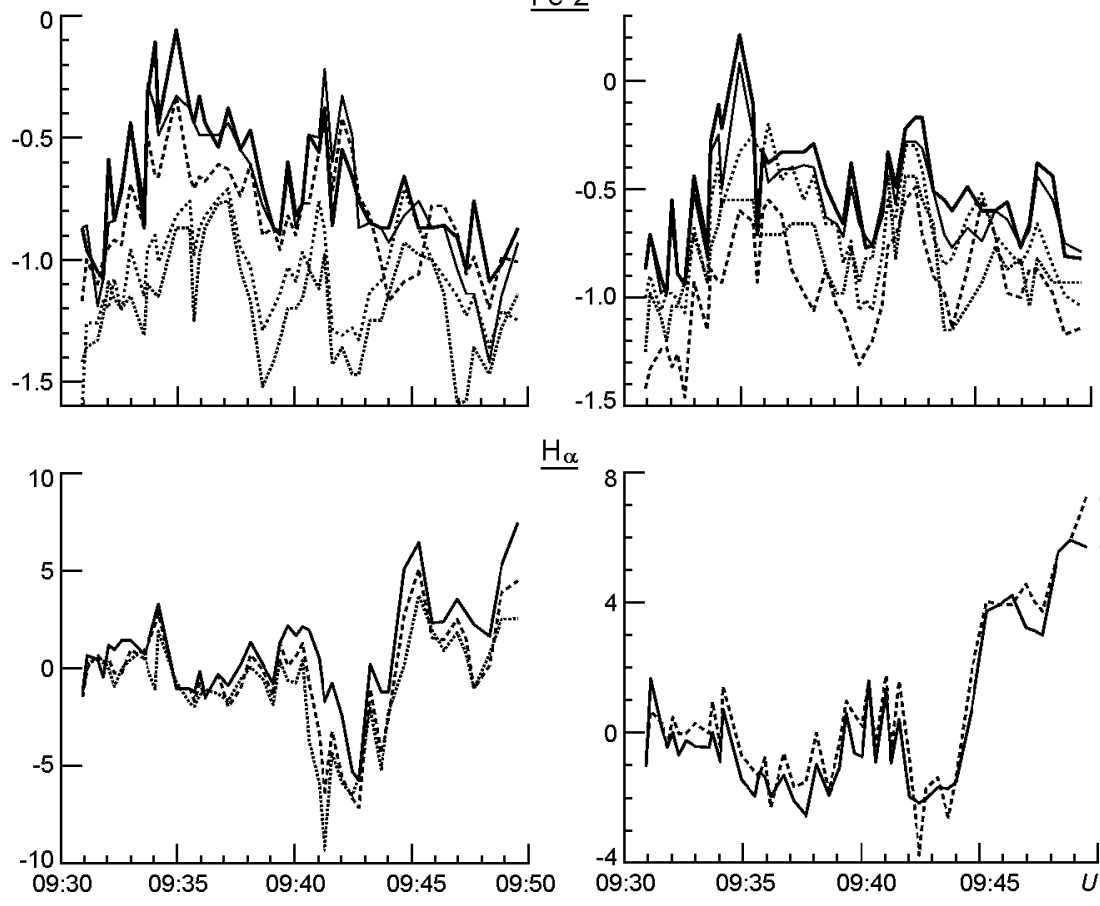

$\underline{H_{\alpha}}$

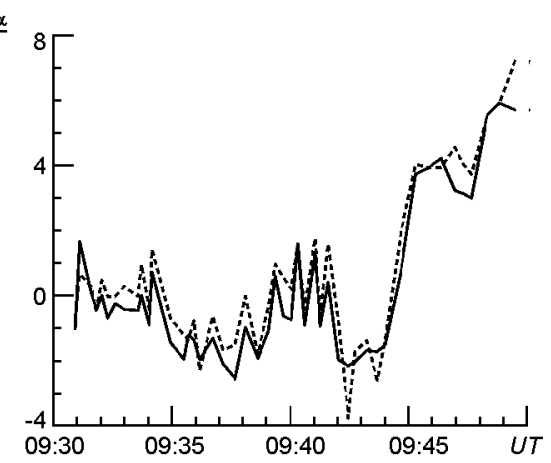

Puc. 6. Изменения со временем лучевых скоростей вещества на разных расстояниях от центральной части БЭ-1 (сечения $1-5$ ) и БЭ-2 (сечения $6-10$ на рис. 5) в верхнем слое фотосферы (линии $\mathrm{Fe}-1$ и $\mathrm{Fe}-2$ ). Для сравнения приведены изменения лучевой скорости на уровне образования ядра линии $\mathrm{H}_{\alpha}$ [7]. Стрелками обозначено время, когда происходили хромосферные выбросы (surges) [7]

Полученные нами значения $V_{\text {луч }}$ были преимущественно отрицательными, т. е. фотосферное вещество на этом участке АО поднималось. Напомним, что АO NOAA 11024 во время наших наблюдений находилась на ранней стадии развития, и исследуемый участок располагался в области нового выходящего магнитного потока [37]. В работе [25] сделан вывод, что общей характеристикой области выходящего магнитного потока является стабильный восходящий поток в фотоcфеpe.

Верхняя фотосфера. БЭ-1. На рис. 6 кривая 1 показывает измене-

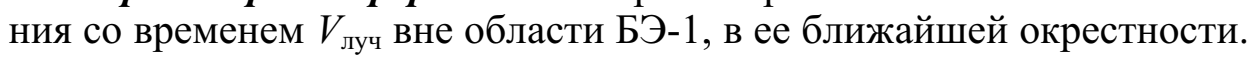



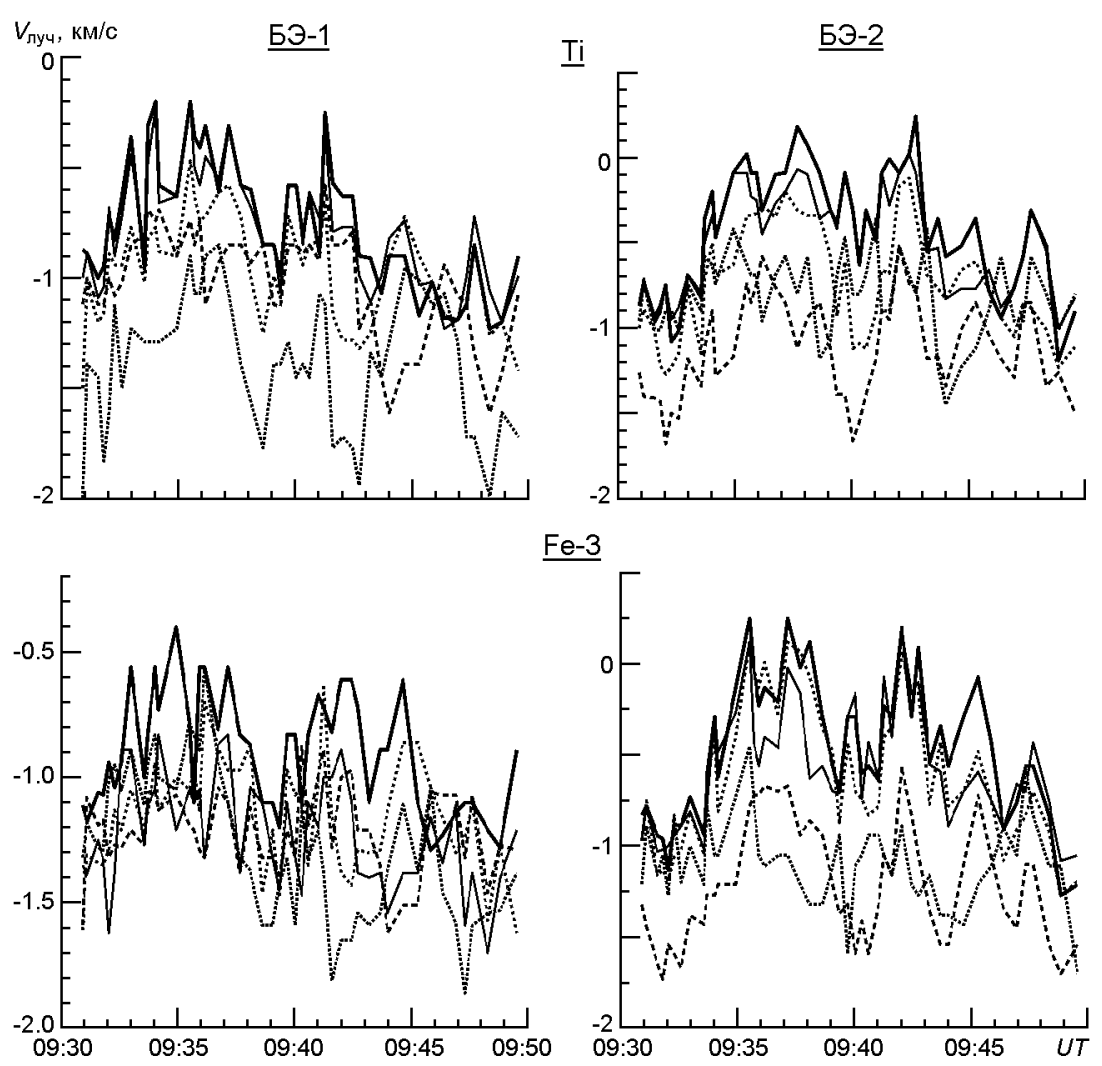

$\underline{\mathrm{Fe}-3}$

Puc. 7. То же, что на рис. 6, но в нижнем слое фотосферы (линии Тi и $\mathrm{Fe}-3$ )

Видно, что на этом участке АО лучевая скорость фотосферного вещества на уровне образования линии $\mathrm{Fe}-1$ изменялась от -1.5 до -0.8 км/с. Вероятно, это была скорость плазмы в выходящем магнитном потоке. Аналогичные результаты получены в работах $[18,27]$. В результате изучения динамики поля скоростей в работе [18] была выявлена область восходящего потока вещества в фотосфере, когда вершина петлеобразной магнитной силовой трубки проходила через нее. Максимальная скорость вещества в потоке достигала 2 км/с. В работе [27] на основе спектрополяриметрических наблюдений нескольких небольших развивающихся биполярных областей по доплеровским сдвигам линий Fe I $\lambda 630.15$ и 630.25 нм было найдено, что в области выходящего потока на уровне фотосферы вещество двигалось преимущественно вверх со скоростью 1.5 км/с.

На кривой 1 хорошо выделяются квазипериодические колебания с интервалом около 4.5 мин и амплитудой около $0.5 \mathrm{~km} / \mathrm{c}$. По сравнению с участком $L_{2}$ в области выходящего магнитного потока, но вне БЭ, интервал между колебаниями $V_{\text {луч }}$ был меньше на $10 \%$, а амплитуда колебаний была меньше в два раза. Вероятно, это указывает на наличие более сильного магнитного поля, чем на участке $L_{2}$.

Кривые $2-4$ относятся к области БЭ-1 (см. рис. 5). Кривая 3 показывает временные изменения фотосферной скорости в области мак- 
симальной яркости БЭ, кривые 2 и 4 - на расстоянии -0.33 и 0.5 Мм от нее, а кривая 5 - на участке АО между БЭ-1 и БЭ-2.

Видно, что наибольшие изменения скорости наблюдались в цент-

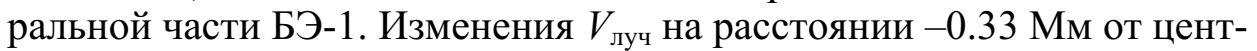
ральной части БЭ (кривая 2) происходили синхронно с изменениями

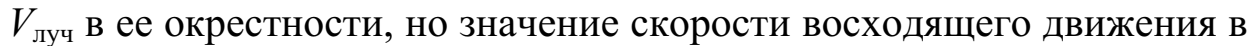
этой области было меньше в среднем на 30 \%. На временных кривых 3 , 4 и 5 выделились два периода (около 6 и 4 мин), состоящие из нескольких пиков, в течение которых значения скорости, направленной к наблюдателю, заметно уменьшались: $9^{h} 32^{m} \ldots 9^{h} 38^{m}$ UT и $9^{h} 39^{m} \ldots 9^{h} 43^{m}$ UT. Максимальное уменьшение скорости (наибольшие пики) произошло около $9^{h} 34^{m}$ UT (скорость восходящего движения вещества уменьшилась по сравнению со скоростью вне БЭ от $-1.2 \mathrm{kм} / \mathrm{c}$ до $0.1 \mathrm{\kappa м} / \mathrm{c}$ ) и около $9^{h} 41^{m}$ UT (скорость уменьшилась от $-0.9 \mathrm{\kappa м} / \mathrm{c}$ до $-0.1 \mathrm{kм} / \mathrm{c})$. Выделился также отдельный пик около $9^{h} 44^{m} 41^{s} \mathrm{UT}$, во

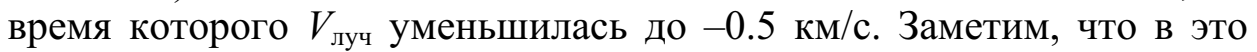
время произошел хромосферный выброс (один из признаков магнитного пересоединения), наблюдался также один из пиков увеличения интенсивности в синем крыле линии $\mathrm{H}_{\alpha}$ и увеличение скорости восходящего движения в хромосфере [7]. Кривая 3 относится к максимуму яркости БЭ-1, однако рис. 6 показывает, что максимальное уменьшение скорости произошло на расстоянии 0.5 Мм (кривая 4) от этого места, т. е. эти максимумы пространственно не совпадали. То, что полное совпадение максимумов интенсивности и скорости, по-видимому, редкое событие в солнечной фотосфере, отмечено в работе [5].

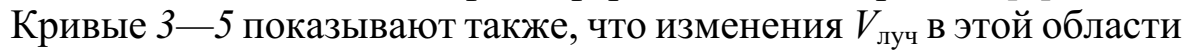

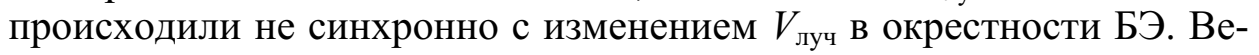
роятно, на квазипериодические колебания скорости, которые хорошо выделялись на участке АО вне БЭ, накладывались изменения скорости, вызванные развитием БЭ-1.

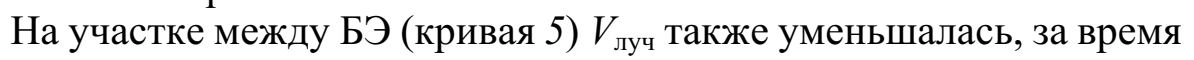
наших наблюдений ее значение изменялось в пределах $-1 \ldots-0.2$ км/с.

К концу наблюдений на этом уровне фотосферы скорость движения вещества вверх в области БЭ-1 увеличилась примерно до $-1 \mathrm{kм} / \mathrm{c}$, ее среднее значение отличалось от среднего значения вне БЭ всего на $7 \%$, ее изменения стали синхронными с изменениями скорости в окрестности БЭ. Напомним, что во время наших наблюдений яркость БЭ-1 уменьшалась, она находилась на стадии затухания. Вероятно, скорость движения фотосферного вещества в это время увеличивалась потому, что уменьшалось влияние БЭ, и основной вклад в вели-

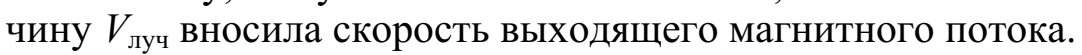

$\mathrm{B}$ области образования $\mathrm{Fe}-2$ и $\mathrm{Fe}-1$ временные изменения лучевой

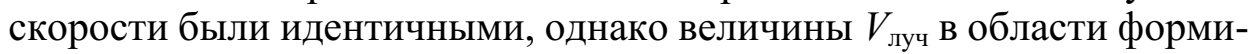
рования $\mathrm{Fe}-2$ были в среднем на $10 . .20 \%$ большими, чем в области формирования Fe-1. Амплитуда и интервал между колебаниями были такими же. Вне БЭ в этом слое фотосферы скорость движения вещества изменялась от -0.8 до -1.6 км/с. В первый период времени макси- 
мальное уменьшение скорости до -0.1 км/с наблюдалось в центральной части БЭ в месте ее максимальной яркости (кривая 3) около $9^{h} 35^{m} \mathrm{UT}$ (примерно на $1^{m}$ позже, чем в области формирования $\mathrm{Fe}-1$ ). Во второй период времени минимальная скорость восходящего движения $V_{\text {луч }}=-0.2 \mathrm{\kappa м} /$ с наблюдалась на расстоянии $0.5 \mathrm{Mм}$ (кривая 4 ) от этого места, около $9^{h} 41^{m}$ UT. Интересно отметить, что на расстоянии -0.33 Мм от центральной части БЭ лучевая скорость уменьшилась в среднем всего на $10 \%$ по сравнению с ее величиной вне БЭ, и ее изме-

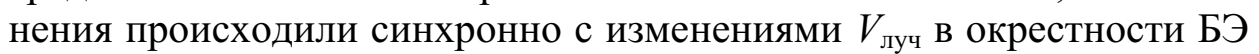
(кривые 1 и 2). На протяжении 0.33 Мм (кривые 2 и 3) скорость движения вещества вверх резко уменьшилась больше чем на 80 \% в первый период времени и примерно на $50 \%$ — во второй. В то же время изменения скорости в области формирования $\mathrm{Fe}-1$ происходили довольно равномерно. К концу наблюдений $V_{\text {луч }}$ в этом слое фотосферы увеличилась в среднем до $-1.2 \mathrm{\kappa м} / \mathrm{c}$.

Верхняя фотосфера. БЭ-2. На рис. 6 кривые $6-9$ относятся к области развития БЭ-2. Кривая 7 показывает временные изменения фотосферной скорости в месте максимальной яркости БЭ-2 (рис. 5), кривые 6,8 и 9 - на расстоянии $-0.33,0.17$ и 0.33 Мм от него, а кривая 10 - на участке АО вне БЭ-2.

На кривых 10 как для $\mathrm{Fe}-1$, так и для $\mathrm{Fe}-2$ хорошо выделяются квазипериодические колебания $V_{\text {луч }}$ с интервалом от 2.5 до 4 мин. Амплитуда колебаний увеличивалась с уменьшением высоты фотосферы и составляла около 0.5 и 0.8 км/с для линий $\mathrm{Fe}-1$ и $\mathrm{Fe}-2$ соответственно.

Видно, что на кривых временного хода лучевой скорости для центральной области БЭ-2, как и для БЭ-1, выделились два периода $\left(9^{h} 32^{m} \ldots 9^{h} 39^{m} \mathrm{UT}\right.$ и $9^{h} 40^{m} \ldots 9^{h} 44^{m} \mathrm{UT}$, которые совпадали с периодами для БЭ-1) и три индивидуальных пика $\left(9^{h} 39^{m} 43^{s}, 9^{h} 45^{m} 00^{s}\right.$ и $9^{h} 47^{m} 41^{s}$ $\mathrm{UT})$, во время которых происходило уменьшение $V_{\text {луч. }}$ На уровне образования Fe-1 наибольшее изменение скорости наблюдалось около

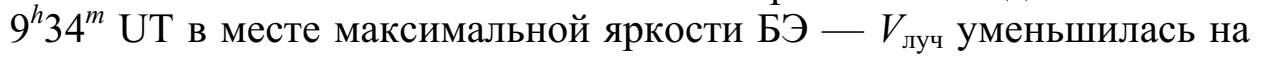

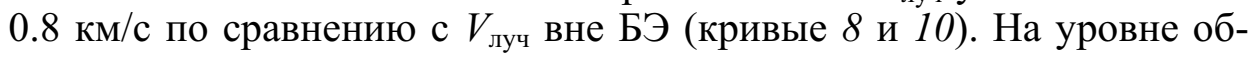
разования $\mathrm{Fe}-2$ максимальное уменьшение скорости на ту же величину наблюдалось минутой позже, в $9^{h} 35^{m} \mathrm{UT}$ (потоки плазмы, уменьшающие скорость восходящего движения, шли сверху). В это время фотосферное вещество опускалось с $V_{\text {луч }}=0.2 \mathrm{\kappa м} / \mathrm{c}$. Во второй период времени скорость уменьшилась до -0.2 км/с. Нужно заметить, что максимальное уменьшение $V_{\text {луч }}$ в этот период времени наблюдалось в $9^{h} 42^{m} 18^{s} \mathrm{UT}$, а в БЭ-1 - на минуту раньше, около $9^{h} 41^{m} 17^{s} \mathrm{UT}$. В конце наблюдений $V_{\text {луч }}$ испытывала колебания в пределах $-0.4 \ldots-0.75$ км/с. В среднем вещество в верхнем слое фотосферы в области БЭ-2 поднималось с меньшей скоростью, чем в области БЭ-1.

Нижжня фотосфера. БЭ-1 и БЭ-2. На рис. 7 показаны изменения со временем $V_{\text {луч }}$ в нижнем слое фотосферы исследуемого участка $\mathrm{AO}$, где формировались линии $\mathrm{Ti}$ и $\mathrm{Fe}-3$.

На уровне образования ядра линии Ті вне БЭ-1 (кривая 1) лучевая скорость изменялась в пределах $-0.9 \ldots-1.9$ км/с, ее значение было в 
среднем в два раза больше, а максимальная амплитуда в 1.5 раза мень-

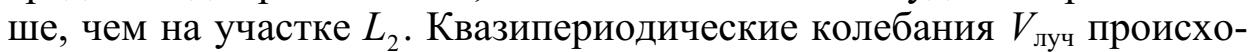
дили с интервалом около 5 мин. Видно, что в центральной области БЭ-1, как и в верхней фотосфере, выделились два периода уменьшения скорости, состоящие из отдельных пиков. В центре БЭ $V_{\text {луч }}$ была меньше в среднем на 70 \%, чем в ее окрестности, сильно уменьшилась амплитуда колебаний (кривые 1 и 3). Минимальные значения скорости движения вещества вверх (около -0.2 км/с) как в первый, так и во второй период пространственно не совпадают с максимальной яркостью БЭ-1 на этом уровне фотосферы на 0.17 Мм. В центральной части БЭ-1 (кривые 2 - 4) и между БЭ (кривая 5) нарушена картина квазипериодических колебаний скорости, которая хорошо видна в об-

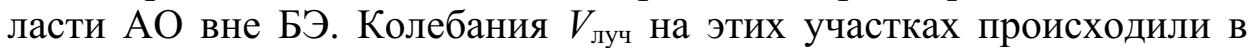

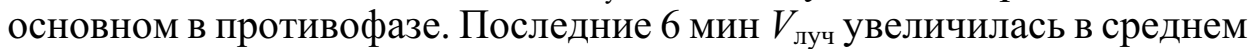
до -1 км/с и испытывала колебания с небольшой амплитудой — около $0.5 \mathrm{KM} / \mathrm{c}$.

В самом нижнем из исследуемых слоев фотосферы, на уровне образования линии $\mathrm{Fe}-3$, максимальное уменьшение скорости в центральной части БЭ-1 до -0.4 км/с наблюдалось около $9^{h} 35^{m} \mathrm{UT}$ (кривая 3). Наибольшие изменения скорости по сравнению с окрестностью БЭ (кривые 1 и 3) произошли во второй период времени $\left(9^{h} 40^{m} \ldots\right.$ $\left.9^{h} 45^{m} \mathrm{UT}\right)$, который состоял из четырех пиков, минимальная $V_{\text {луч }}$ в момент наблюдения $9^{h} 42^{m} 10^{s} \mathrm{UT}$ была около $-0.6 \mathrm{\kappa m} / \mathrm{c}$, на $1.2 \mathrm{kм} / \mathrm{c}$ меньше, чем $V_{\text {луч }}$ вне БЭ. Заметим, что на этом уровне фотосферы в неко-

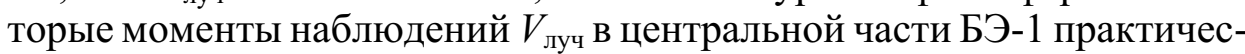
ки не отличалась от $V_{\text {луч }}$ вне БЭ, а в некоторые моменты разница между ними доходила до 1.2 км/с. В других слоях фотосферы, которые мы исследовали, в центральной части БЭ скорость вещества была значительно меньше, чем вне БЭ-1. Изменения $V_{\text {луч }}$ со временем в этом слое фотосферы в центральной области БЭ-1 и вне ее происходили в основном в противофазе (кривые 1 и 3 ).

Как видно на рис. 7, в области развития БЭ-2 (кривые 6-8) на уровне формирования линий Тi и $\mathrm{Fe}-3$ скорость движения вещества была меньшей, чем в области развития БЭ-1. В начале наблюдений

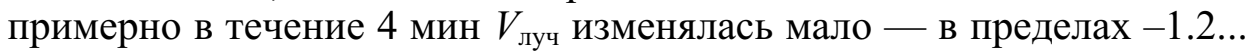
-0.7 км/с, испытывая колебания с небольшой амплитудой. Затем скорость восходящего движения вещества резко уменьшилась. Как и в

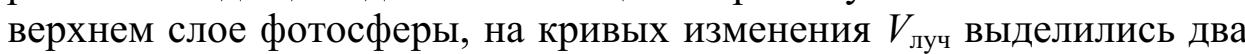
периода времени уменьшения скорости плазмы. Как в первый, так и во второй период времени в центральной области БЭ-2 на этом уровне фотосферы наблюдалось даже опускание вещества со скоростью до $0.25 \mathrm{kм} / \mathrm{c}$. По сравнению с окрестностью БЭ скорость уменьшилась в среднем на $1.3 \mathrm{\kappa м} / \mathrm{c}$.

Заметим, что наибольшие изменения $V_{\text {луч }}$ в области БЭ-1 произошли в верхнем слое фотосферы, а в области БЭ-2 - в нижнем.

Скорость фотосферного вещества в выходящем магнитном

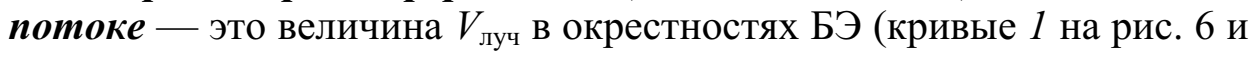


7). Кривые 1 для всех исследованных уровней фотосферы хорошо коррелируют между собой. В течение наших наблюдений среднее значение $V_{\text {луч }}$ в потоке составляло около -1.4 км/с (в пределах от $V_{\text {луч }}$ $=-0.8$ до $\left.V_{\text {луч }}=-2 \mathrm{\kappa м} / \mathrm{c}\right)$, в то время как средняя величина лучевой скорости на участке $L_{2}$ была больше чем в два раза меньшей, и составляла около $0.6 \mathrm{~km} / \mathrm{c}$. Это свидетельствует о наличии более сильного магнитного поля на участке $L_{1}$. Наши результаты согласуются с выводами работ [18, 27], где получены оценки скорости вещества в выходящем магнитном потоке - около 1.5 и 2 км/с.

Интересно отметить, что пики увеличения интенсивности всех исследованных в работе линий, хорошо выделяющиеся на временных кривых яркости для БЭ-1 в начале наблюдений, почти не видны на тех

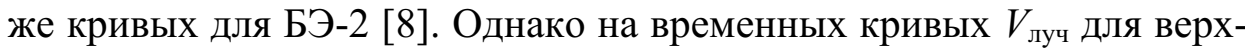
него слоя фотосферы БЭ-2 пики резкого уменьшения скорости восходящего движения вещества в начале наблюдений хорошо выделяются. Это указывает на то, что изменения скорости фотосферного вещества в области образования БЭ-2 происходили раньше изменений ее яркости. Вероятно, это является подтверждением вывода, сделанного в работах $[16,22,23]$ о том, что изменения скорости вызывают деформацию магнитного поля, необходимую, чтобы вызвать вынужденные повторные пересоединения.

На рис. 8 показаны изменения $V_{\text {луч }}$ со временем на участке $\mathrm{AO}$, вырезанном щелью спектрографа, на разных уровнях фотосферы. Хорошо видно, что временные изменения лучевой скорости вещества в областях БЭ на всех исследованных уровнях фотосферы носили колебательный характер и хорошо коррелировали между собой. Видно также, что выделились два периода уменьшения скорости восходящего движения вещества, к концу наблюдений $V_{\text {луч}}$, в области БЭ-1 увеличивалась, а в области БЭ-2 изменилась мало. В работе [28] было найдено, что изменения фотосферных скоростей в области БЭ хорошо коррелируют с временными изменениями эмиссии в крыле $\mathrm{H}_{\alpha}$. Этот вывод подтверждает и наше исследование, если сравнить рис. 8 и рис. 12в в работе [8], на котором приведены временные изменения интенсивности в красном крыле линии $\mathrm{H}_{\alpha}$. Видно также, что изменения лучевой скорости фотосферного вещества в областях развития БЭ происходили синхронно, т. е. они составляли физически связанную пару.

В каком слое атмосферы Солнца произошли магнитные пересоединения, вызвавшие развитие БЭ? В начале наблюдений на времен-

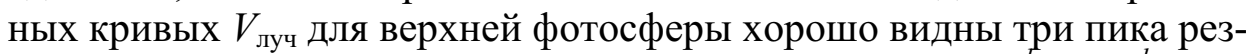
кого уменьшения скорости восходящего движения - в $9^{h} 32^{m}, 9^{h} 33^{m}$ и в $9^{h} 34^{m} \mathrm{UT}$, которые хорошо согласуются с пиками увеличения интенсивности в крыльях линии $\mathrm{H}_{\alpha}$ (см. рис. 6а в работе [7]), а также пиками увеличения яркости БЭ-1 в разных слоях фотосферы (рис. 10, 11 в работе [8]) и являются признаком импульсного выделения энер-

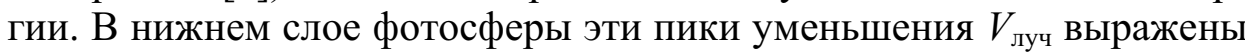
слабо. В работе [8] сделан вывод, что в результате выхода нового маг- 

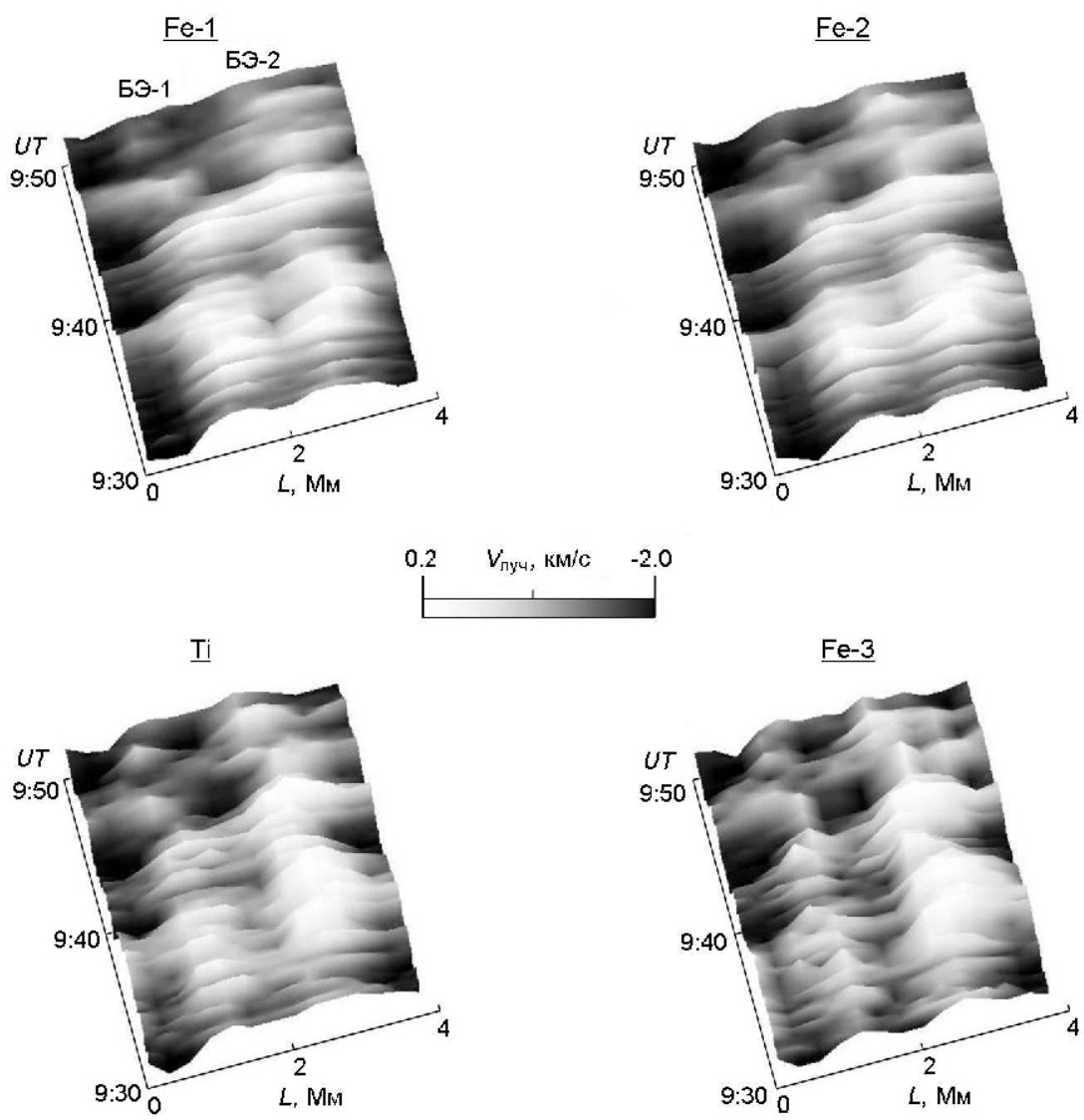

Puc. 8. Изменения лучевых скоростей вещества со временем вдоль щели спектрографа на разных уровнях фотосферы

нитного потока произошли последовательные магнитные пересоединения в области БЭ-1, возбуждение распространилось вдоль магнитной петли и вызвало появление БЭ-2, затем они развивались как физически связанная пара. В области образования ядра линии $\mathrm{H}_{\alpha}$ (рис. 6) в это время наблюдались как опускание, так и подъем вещества с небольшой скоростью, поэтому трудно сказать, где происходили магнитные пересоединения. Можно предположить, что они происходили близко к верхней фотосфере, поэтому наблюдалось сильное понижение скорости движения фотосферного вещества вверх (наблюдалось даже движение вещества вниз с небольшой скоростью до 0.2 км/с), но не был затронут слой хромосферы на уровне формирования ядра линии $\mathrm{H}_{\alpha}$. Но второй период понижения скорости подъема фотосферного вещества $\left(9^{h} 39^{m} \ldots 9^{h} 43^{m}\right.$ UT у БЭ-1 и $9^{h} 40^{m} \ldots 9^{h} 44^{m}$ UT у БЭ-2) хорошо согласуется с периодом времени $\left(9^{h} 40^{m} 20^{s} . . .9^{h} 44^{m} 20^{s}\right.$ UT [7]), когда на уровне хромосферы наблюдался восходящий поток, который имел три пика увеличения скорости. На рис. 6 видно, что в области БЭ-1 в $9^{h} 41^{m} 15^{s}$ UT лучевая скорость увеличилась до -9.3 км/с, второй пик был приблизительно через 1.5 мин, максимальная скорость в нем достигла $-7.0 \mathrm{kм} / \mathrm{c}$, а третий пик наблюдался еще через минуту, с 
максимальным значением $V_{\text {луч }}=-5.2 \mathrm{\kappa m} / \mathrm{c}$. В области БЭ-2 период подъема вещества с $9^{h} 42^{m}$ до $9^{h} 44^{m} 30^{s}$ UT имел два максимума увеличения скорости: примерно до -4.0 и -2.5 км/с. Это указывает на то, что в это время наблюдалось разнонаправленное движение - в нижнем слое хромосферы вещество двигалось вверх, в то же время образовались потоки вещества, которые двигались вниз, уменьшая скорость восходящего движения плазмы на уровне фотосферы. Такое распределение скоростей могли вызвать магнитные пересоединения, которые происходили в слое между верхней фотосферой и нижней хромосферой, где формировалось ядро линии $\mathrm{H}_{\alpha}$. Известно, что одним из признаков происходящего пересоединения является образование выброса. Действительно, в это же время, около $9^{h} 43^{m} \mathrm{UT}$, в области БЭ-2 наблюдался небольшой хромосферный выброс [7].

\section{ОБСУЖДЕНИЕ РЕЗУЛЬТАТОВ И ВЫВОДЫ}

В работе представлены результаты анализа особенностей изменений лучевых скоростей плазмы в разных слоях фотосферы активной области NOAA 11024 под действием двух возникших и развивающихся бомб Эллермана (БЭ-1 и БЭ-2). В день наблюдений, 4 июля 2009 г., АО находилась на стадии резкого роста активности, и бомбы Эллермана развивались в области одного из трех выходящих в это время магнитных потоков. Во время наших наблюдений БЭ-1 находилась на стадии затухания, а яркость БЭ-2 увеличивалась. Использован участок спектра вблизи $\lambda=630$ нм, включающий фотосферные линии, которые формируются в большом диапазоне высот. Определены и проанализированы изменения скорости и направления движения вещества в областях бомб Эллермана и в их ближайших окрестностях на разных уровнях фотосферы и на разных стадиях развития БЭ. Для сравне-

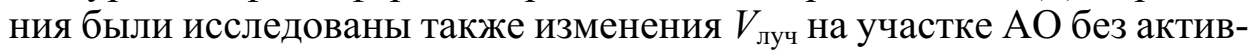
ных образований и вне областей выходящих магнитных потоков. Были использованы $I$-профили Стокса, полученные с интервалом, соответствующим расстоянию на Солнце 160 км.

Исследования показали, что на всех уровнях фотосферы в областях БЭ и их окрестностях происходил преимущественно подъем вещества. При этом в местах расположения БЭ наблюдалось заметное уменьшение величины лучевых скоростей и амплитуды их колебаний. Вероятно, сверху шли потоки вещества, которые уменьшали скорость восходящего движения плазмы. Это указывает на то, что мелкомасштабные нисходящие движения, вызванные магнитными пересоединениями, накладывались на крупномасштабное восходящее движение плазмы нового магнитного потока. Этот вывод подтверждает и форма профилей фотосферных линий. Профили сильных линий, которые формировались в верхнем слое фотосферы, имели красную асимметрию. Вероятно, это связано с наличием в этой области нисходящих струй плазмы. Профили слабых линий, формировавшихся в нижнем 
слое фотосферы, имели несколько компонентов в красном крыле. Скорость вещества, определенная по смещению компонента, который хорошо выделялся в красном крыле профилей линии $\mathrm{Fe} I \lambda 630.35$ нм,

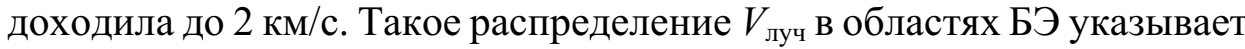
на то, что они состояли из нескольких струй, движущихся с разными скоростями и в разных направлениях.

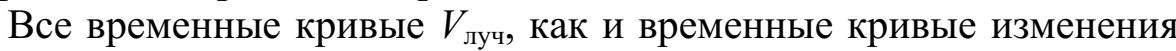
яркости [8], представляли собой ряд последовательных пиков, указывая на то, что выделение энергии в бомбах Эллермана происходило в результате последовательных прерывистых магнитных пересоединений. Выделились два периода времени (около 6 и 4 мин), состоящие из нескольких пиков, в течение которых скорость восходящего движения фотосферного вещества существенно уменьшалась. В среднем фотосферное вещество в области БЭ-2 поднималось с меньшей скоростью, чем в области БЭ-1, в некоторые моменты наблюдалось даже опускание с небольшой скоростью, до 0.2 км/с. В центральной части БЭ-1 и БЭ-2 в верхнем слое фотосферы лучевая скорость изменялась в пределах $-1 \ldots 0$ и $-1 \ldots 0.2 \mathrm{kм} / \mathrm{c}$, в нижнем слое фотосферы - в пределах $-1.6 \ldots-0.2$ и $-1.1 \ldots 0.25 \mathrm{\kappa м} / \mathrm{c} \mathrm{соответственно.}$

Изменения скорости в период образования БЭ-2 (первые 4 мин наших наблюдений) произошли раньше, чем увеличилась ее яркость.

Во время развития БЭ при увеличении их яркости скорость восходящего движения вещества уменьшалась, но не всегда максимум яркости БЭ пространственно совпадал с максимумом уменьшения скорости.

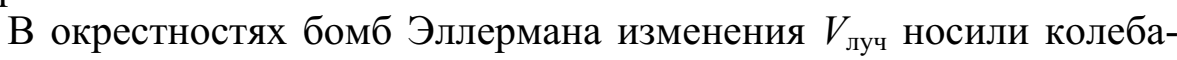
тельный характер, интервал между колебаниями составлял около 5 мин. В областях БЭ картина квазипериодических колебаний $V_{\text {луч }}$ нарушалась, во многих случаях они происходили в противофазе. Вероятно, на квазипериодические колебания скорости, которые хорошо выделялись на участке АО вне БЭ накладывались изменения скорости вызванные развитием БЭ.

Данная работа является продолжением работ [7, 8], в которых представлены результаты анализа спектральных наблюдений БЭ-1 и БЭ-2 в линии $\mathrm{H}_{\alpha}$, а также рассмотрены особенности изменений фраунгоферовых линий, образующихся в разных слоях фотосферы, в спектрах бомб Эллермана и их окрестностей, полученных на разных стадиях развития БЭ. На основе проведенных исследований можно сделать вывод, что возбуждение, вызванное импульсным выделением энергии в результате последовательных магнитных пересоединений, связанных с выходом нового магнитного потока, распространилось из области БЭ-1 вдоль магнитной петли и вызвало появление БЭ-2, затем они развивались как физически связанная пара. Изученные особенности изменения лучевых скоростей хромосферного и фотосферного вещества указывает на то, что во время развития БЭ наблюдалось разнонаправленное движение - в нижнем слое хромосферы вещество двигалось вверх, а также образовались потоки, которые двигались 
вниз, уменьшая скорость восходящего движения плазмы на уровне фотосферы. Такое распределение скоростей могли вызвать магнитные пересоединения, которые происходили в слое между верхней фотосферой и нижней хромосферой, где формировалось ядро линии $\mathrm{H}_{\alpha}$.

Автор выражает благодарность Е. В. Хоменко и Р. И. Костыку за материалы наблюдений на франко-итальянском солнечном телескопе THEMIS и программы по их обработке.

1. Гуртовенко Э. А., Костык Р. И. Фраунгоферов спектр и система солнечных сил осцилляторов. К.: Наук. Думка, 1989. 200 с.

2. Коваль А. Н. О движениях, связанных с усами. Изв. КрАО. 1964. 32. С. 32-37.

3. Костык Р. И., Щукина Н. Г. Пятиминутные колебания и тонкая структура фотосферы Солнца. І. Кинематика и физика небес. тел. 1999. 15. № 1. С. 2537.

4. Костык Р. И., Щукина Н. Г. Пятиминутные колебания и тонкая структура фотосферы Солнца. II. Кинематика и физика небес. тел. 1999. 15. № 2. C. $135-144$.

5. Костык Р. И., Щукина Н. Г. Тонкая структура конвективных движений в фотосфере Солнца: наблюдения и теория. Астрон. журн. 2004. 81. № 9. C. $846-858$.

6. Пасечник М. Н. Движение плазмы в солнечной петле в выходящем магнитном потоке. Кинематика и физика небес. тел. 2014. 30. № 4. С. 233-242.

7. Пасечник М. Н. Спектральное исследование пары бомб Эллермана. Кинематика и физика небес. тел. 2016. 32. № 2. С. 3-24.

8. Пасечник М. Н. Спектральное исследование бомб Эллермана. Фотосфера. Кинематика и физика небес. тел. 2018. 34. № 2. С. 25-45.

9. Северный А. Б. Некоторые результаты исследования нестационарных процессов на Солнце. Астрон. журн. 1957. 34. С. 684-693.

10. Archontis V., Hood A. W. Formation of Ellerman bombs due to 3D flux emergence. Astron. and Astrophys. 2009. 508. P. 1469-1483.

11. Berlicki A., Heinzel P. Observations and NLTE modeling of Ellerman bombs. Astron. and Astrophys. 2014. 567. P. 1-10. Vol. 567, id. A110, 10 p.

12. Berlicki A., Heinzel P., Avrett E. H. Photometric analysis of Ellerman bombs. Mem. Soc. astron. ital. 2010. 81. P. 646-652.

13. Chae J., Moon Y.-J., Park S.-Y. Observational test of chromospheric magnetic reconnection. J. Korean Astron. Soc. 2003. 36. S1. P. 13-20.

14. Ellerman F. Solar hydrogen "bombs". Astrophys. J. 1917. 46. P. 298-301.

15. Engell A. J., Siarkowski M., Gryciuk M., et al. Flares and their underlying magnetic complexity. Astrophys. J. 2011. 726. P. 12-20.

16. Fang C., Tang Y. H., Xu Z., et al. Spectral analysis of Ellerman bombs. Astrophys. J. 2006. 643. P. 1325-1336.

17. Georgoulis M. K., Rust D. M., Bernasconi P. N., et al. Statistics, morphology, and energetics of Ellerman bomb. Astrophys. J. 2002. 575. P. 506-528.

18. Grigor'ev V. M., Ermakova L. V., Khlystova A. I. The dynamics of photospheric line-of-sight velocities in emerging active regions. Astron. Reps. 2011. 55. N 29. P. 163-173.

19. Guglielmino S. L., Bellot Rubio L. R., Zuccarello F., et al. Multiwavelength observations of small-scale reconnection events triggered by magnetic flux emergence in the solar atmosphere. Astrophys. J. 2010. 724. P. 1083-1098.

20. Hashimoto Yu., Kitai R., Ichimoto K., et al. Internal fine structure of Ellerman bombs. Publs Astron. Soc. Jap. 2010. 62. P. 879-891. 
21. Herlender M., Berlicki A. Multi-wavelength analysis of Ellerman bomb light curves. Cent. Eur. Astrophys. Bull. 2011. 35. P. 181-186.

22. Kitai R. On the mass motions and the atmospheric states of moustaches. Solar Phys. 1983. 87. P. 135-154.

23. Kitai R. Ellerman bomb as a manifestation of chromospheric fine scale activity. The Fifth Hinode Science Meeting. ASP Conference Series, Vol. 456, Proc. of a conference held 10-14 October 2011 at Royal Sonesta Hotel, Cambridge, Massachusetts. Edited by L. Golub, I. De Moortel and T. Shimizu. San Francisco: Astron. Soc. Pacif. 2012. P. 81 .

24. Kondrashova N. N., Pasechnik M. N., Chornogor S. N., et al. Atmosphere dynamics of the active region NOAA 11024. Solar. Phys. 2013. 284. N2. P. 499-513.

25. Kozu H., Kitai R., Brooks, D. H., et al. Horizontal and vertical flow structure in emerging flux regions. Publs Astron. Soc. Jap. 2006. 58. P. 407-421.

26. Kurokawa H., Kawaguchi I., Funakoshi Y., et al. Morphological and evolutional features of Ellerman bombs. Solar. Phys. 1982. 79. P. 77-84.

27. Lites B. W., Skumanich A., Martinez Pillet V. Vector magnetic fields of emerging solar flux I. Properties at the site of emergence. Astron. and Astrophys. 1998. 333. P. 1053-1068.

28. Matsumoto T., Kitai R., Shibata K., et al. Height dependence of gas flows in an Ellerman bomb. Publ. Astron. Soc. Jap. 2008. 60. P. 95-102.

29. Matsumoto T., Kitai R., Shibata K., et al. Cooperative observation of Ellerman bombs between the Solar Optical Telescope aboard Hinode and Hida/Domeless Solar Telescope. Publ. Astron. Soc. Jap. 2008. 60. P. 577-585.

30. Nelson C. J., Doyle J. G., Erdelyi R., et al. Statistical Analysis of Small Ellerman Bomb events. Solar. Phys. 2013. 283. N 2. P. 307-323.

31. Nelson C. J., Shelyag S., Masthioudakis M., et al. Ellerman bombs - evidence for magnetic reconnection in the lower solar atmosphere. Astrophys. J. 2013. 779. P. $125-135$.

32. Pariat E., Schmieder B., Berlicki A., et al. Spectrophotometric analysis of Ellerman bombs in the $\mathrm{Ca}$ II, $\mathrm{H}_{\alpha}$, and UV range. Astron. and Astrophys. 2007. 473. P. 279289.

33. Qiu J., Ding M. D., Wang H., et al. Ultraviolet and $\mathrm{H}_{\alpha}$ emission in Ellerman bombs. Astrophys. J. 2000. 544. P. LI 57-L161.

34. Rezaei R., Beck C. Multiwavelength spectropolarimetric observations of an Ellerman bomb. Astron. and Astrophys. 2015. 582.13 p. id. A104.

35. Rutten R. J. $\mathrm{H}_{\alpha}$ features with hot onsets I. Ellerman bombs. Astron. and Astrophys. 2016. 590. P. 124-137.

36. Socas-Navarro H., Martínez Pillet V., Elmore D., et al. Spectro-polarimetric observations and non-LTE modeling of ellerman bombs. Solar. Phys. 2006. 235. N 1-2. P. $75-86$.

37. Valori G., Green L. M., Demouli P., et al. Nonlinear force-free extrapolation of emerging flux with a global twist and serpantine fine structures. Solar Phys. 2012. 278. N 1. P. $73-97$.

38. Vissers G. J. M., Rouppe van der Voort L. H. M., Rutten R. J. Ellerman bombs at high resolution. II. Triggering, visibility, and effect on upper atmosphere. Astrophys. J. 2013. 774. P. 32-46.

39. Watanabe H., Kitai R., Okamoto K., et al. Spectropolarimetric observation of an emerging flux region: triggering mechanisms of Ellerman bombs. Astrophys. $J$. 2008. 684. P. 736-746.

40. Watanabe H., Vissers G., Kitai R., et al. Ellerman bombs at high resolution: 1. Morphological evidence for photospheric reconnection. Astrophys. J. 2011. 736. P. 71-83.

41. Zachariadis Th. G., Alissandrakis C. E., Banos G. Observations of Ellerman bombs in $\mathrm{H}_{\alpha}$. Solar Phys. 1987. 108. N2. P. 227-236. 
Стаття надійшла до редакції 08.11.2018

Після доробки 24.11.2018

Прийнята до друку 06.12.2018

М. М. Пасечник

Головна астрономічна обсерваторія Національної академії наук України Київ, Україна

\section{РУХ ФОТОСФЕРНОЇ РЕЧОВИНИ НА ДІЛЯНЦІ АКТИВНОЇ ОБЛАСТІ 3 ДВОМА БОМБАМИ ЕЛЛЕРМАНА}

Представлено результати аналізу особливостей змін променевих швидкостей плазми в різних шарах фотосфери активної області NOAA 11024 під дією двох бомб Еллермана (БЕ-1 і БЕ-2), які виникли і розвивалися. Спектральні дані з високою просторовою та часовою роздільністю було отримано на франко-італійському сонячному телескопі THEMIS 4 липня 2009 р. Час спостережень склав 20 хв. У день спостережень АО перебувала на стадії різкого зростання активності, і бомби Еллермана розвивалися в області одного з трьох магнітних потоків, що виходили в цей час. Під час наших спостережень БЕ-1 перебувала на стадії затухання, а яскравість БЕ-2 збільшувалася. Використано ділянку спектру $\lambda \approx 630$ нм, яка включає фотосферні лінії, що формуються у великому діапазоні висот: лінії нейтрального заліза Fe I $\lambda$ $630.15,630.25,630.35$ нм та лінію титану Ті I $\lambda 630.38$ нм. Визначено і проаналізовано зміни швидкості і напрямку руху речовини в областях бомб Еллермана та їхніх найближчих околиць на різних рівнях фотосфери та на різних стадіях розвитку БЕ. Дослідження показали, що на всіх рівнях фотосфери АО відбувався переважно підйом речовини. При цьому в місцях розташування БЕ спостерігалося помітне зменшення величини променевих швидкостей $V_{\text {пр }}$ і амплітуди їхніх коливань. Ймовірно, зверху йшли потоки речовини, які зменшували швидкість висхідного руху плазми. Це вказує на те, що дрібномасштабні низхідні рухи, викликані магнітними перез'єднаннями, накладалися на великомасштабний висхідний рух плазми нового магнітного потоку. Цей висновок підтверджує і форма профілів фотосферних ліній. Профілі сильних ліній мали червону асиметрію. Швидкість речовини, визначена за зміщенням компонента, який добре виділявся у червоному крилі профілів лінії

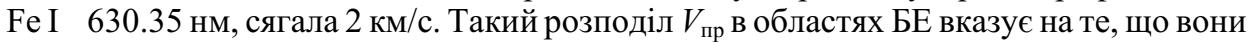
складалися 3 декількох струменів, які рухались з різними швидкостями і в різних напрямках. У центральній частині БЕ-1 та БЕ-2 у верхньому шарі фотосфери променева швидкість змінювалася у межах $-1 \ldots 0$ та $-1 \ldots 0.2$ км/с, в нижньому шарі фотосфери - у межах $-1.6 \ldots-0.2$ км/с та $-1.1 \ldots 0.25$ км/с відповідно. В околицях бомб Ел-

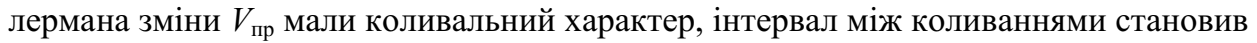

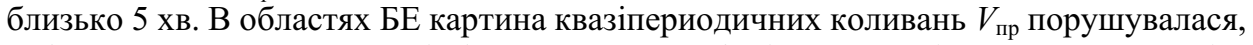
у багатьох випадках вони відбувалися у протифазі. На основі проведених досліджень можна зробити висновок, що збудження, викликане імпульсним виділенням енергії в результаті послідовних магнітних перез'єднань, пов'язаних з виходом нового магнітного потоку, поширилося 3 області БЕ-1 вздовж магнітної петлі і викликало появу БЕ-2, потім вони розвивалися як фізично пов'язана пара. Вивчені особливості зміни променевих швидкостей хромосферної та фотосферної речовини вказує на те, що під час розвитку БЕ спостерігався різноспрямований рух — в нижньому шарі хромосфери речовина рухалася вгору, а також утворилися потоки, які рухалися вниз, зменшуючи швидкість висхідного руху плазми на рівні фотосфери. Такий розподіл швидкостей могли викликати магнітні перез'єднання, які відбувалися в шарі між верхньою фотосферою та нижньою хромосферою, де формувалося ядро лінії $\mathrm{H}_{\alpha}$.

Ключові слова: Сонце, фотосфера, бомби Еллермана, спектральне дослідження, променеві швидкості. 


\author{
M. N. Pasechnik \\ Main Astronomical Observatory of the National Academy of Sciences of Ukraine \\ Kyiv, Ukraine

\section{MOTION OF THE PHOTOSPHERIC MATTER IN THE ACTIVE REGION SITE WITH TWO ELLERMAN BOMBS}

The results of the feature changes analysis of the line-of-sight velocities plasma in different layers of the photosphere of the active region NOAA 11024 under the action appeareing and developing two Ellerman bombs (EB-1 and EB-2) are presented. Spectral data with high spatial and temporal resolution (about 3 seconds) were obtained with the French- Italian solar telescope THEMIS on July 4, 2009. The observation time was 20 minutes. On the day of the observations, the AR was at the stage of a sharp increase in activity and the Ellerman bombs developed in the region of one of the three magnetic fluxes that were emerging at this time. The brightness of EB-1 decreased in the process of observations, while the brightness of EB-2 increased. We used a spectral region of $\lambda \approx 630 \mathrm{~nm}$, which included four Fraunhofer lines that are formed over a wide range of photospheric heights: the neutral iron lines Fe I $\lambda 630.15 \mathrm{~nm}, 630.25 \mathrm{~nm}, 630.35 \mathrm{~nm}$ and the titanium line Ti I $\lambda$ $630.38 \mathrm{~nm}$. Changes in the velocity and direction of motion of matter in the areas of Ellerman bombs and in their immediate vicinity at different levels of the photosphere and at different stages of EBs development are determined and analyzed. Studies have shown that at all levels of the AR photosphere predominantly upflows were observed. At the same time, a noticeable decrease of the line-of-sight velocity magnitudes and the amplitude of their oscillations was observed at the location of the EBs. This indicates that small-scale downward movements were superimposed on the large-scale upward motion of the plasma new magnetic flux. This conclusion is confirmed by the shape of photospheric line profiles. The profiles of strong lines had a red asymmetry. The velocity of the matter, determined by the component displacement, which stood out well in the red wing of the Fe I $\lambda 630.35 \mathrm{~nm}$ line profiles, reached $2 \mathrm{~km} / \mathrm{s}$. Such a distribution of $V_{L O S}$ in the EB regions indicates that they consisted of several jets moving at different velocities and in different directions. In the central part of the EB-1 and EB-2 in the upper layer of the photosphere, the line-of-sight velocity varied between $-1 \ldots 0 \mathrm{~km} / \mathrm{s}$ and $-1 \ldots 0.2 \mathrm{~km} / \mathrm{s}$, in the lower layer of the photosphere - between $-1.6 \ldots-0.2 \mathrm{~km} / \mathrm{s}$ and $-1.1 \ldots 0.25 \mathrm{~km} / \mathrm{s}$, respectively. In the vicinities of the Ellerman bombs, the variations of $V_{L O S}$ were oscillatory, the interval between oscillations was about 5 minutes. In the EB regions, the picture of quasiperiodic oscillations of the $V_{L O S}$ was disturbed, in many cases they occurred in antiphase. Based on the research, it can be concluded that the excitation caused by pulsed energy release as a result of successive magnetic reconnections associated with the release of a new magnetic flux propagated from the EB-1 area along the magnetic loop and initiated the formation of EB-2, then they developed as physically connected pair. The studied features of the temporal changes in the line-of-sight velocity of the chromospheric and photospheric matter in the Ellerman bomb regions and their vicinity indicate that during the development of EBs, multidirectional movement was observed - in the lower chromospheric layer the matter moved upward, and also streams formed that moved downward, reducing the velocities of the ascending plasma at the photospheric level. Such a distribution of velocities could cause magnetic reconnections that occurred in the layer between the upper photosphere and the lower chromosphere, where the core of the $\mathrm{H}_{\alpha}$ line was formed.

Keywords: Sun, photosphere, Ellerman bombs, spectral research, line-of-sight velocities. 